UNIVERSIDADE DE SÃO PAULO

FACULDADE DE MEDICINA DE RIBEIRÃO PRETO

TALITA PEREZ SANCHES

CARACTERIZAÇÃo DO NICHO ENDOSTEAL NAS NEOPLASIAS MIELOPROLIFERATIVAS ASSOCIADAS À MUTAÇÃo JAK2V617F 
TALITA PEREZ SANCHES

\section{CARACTERIZAÇÃO DO NICHO ENDOSTEAL NAS \\ NEOPLASIAS MIELOPROLIFERATIVAS ASSOCIADAS À \\ MUTAÇÃO JAK2V617F}

A versão original após corrigida estará disponível tanto na Biblioteca da Unidade que aloja o Programa, quanto na Biblioteca Digital de Teses e Dissertações da USP.

Dissertação apresentada à Faculdade de Medicina de Ribeirão Preto da Universidade de São Paulo para obtenção do título de Mestre em Ciências, Programa de Oncologia Clínica, Células-Tronco e Terapia Celular.

Área de concentração: Diferenciação celular normal e neoplásica.

Orientadora: Profa. Dra. Lorena Lobo de Figueiredo Pontes

RIBEIRÃO PRETO

2020 
Autorizo a reprodução e divulgação total ou parcial deste trabalho, por qualquer meio convencional ou eletrônico, para fins de estudo e pesquisa, desde que citada a fonte.

Catalogação na publicação

Serviço de Biblioteca e Documentação Médica

Faculdade de Medicina de Ribeirão Preto da Universidade de São Paulo

Sanches, Talita Perez

Caracterização do nicho endosteal nas neoplasias mieloproliferativas associadas à mutação JAK2V617 - Ribeirão Preto, 2020.

$43 f$

Dissertação (mestrado), apresentada à Faculdade de Medicina de Ribeirão Preto da Universidade de São Paulo, Programa de Oncologia Clínica, CélulasTronco e Terapia Celular.

Orientador: Figueiredo-Pontes, Lorena Lobo de

1.Nicho endosteal. 2. Mutação da JAK2. 3. Neoplasias mieloproliferativas 


\section{FOLHA DE APROVAÇÃO}

\section{TALITA PEREZ SANCHES}

Caracterização do nicho endosteal nas neoplasias mieloproliferativas associadas à mutação JAK2V617F

Dissertação apresentada à Faculdade de Medicina de Ribeirão Preto da Universidade de São Paulo para obtenção do título de Mestre em Ciências, Programa de Oncologia Clínica, Células-Tronco e Terapia Celular.

Área de concentração: Diferenciação celular normal e neoplásica.

Aprovado em:

Banca Examinadora

Prof. Dr.: Instituição:

Julgamento: Assinatura:

Prof. Dr.: Instituição:

Julgamento: Assinatura:

Prof. Dr. Instituição:

Julgamento: Assinatura: 


\section{DEDICATÓRIA}

Dedico este trabalho, primeiramente, a Deus, que me deu forças para vencer todas as dificuldades. Aos meus pais, porque minhas conquistas são deles. À minha orientadora e nosso grupo de pesquisa, conseguimos! 


\section{AGRADECIMENTOS}

Se você está lendo esta página é porque eu consegui. E não foi fácil chegar até aqui. Do processo seletivo, passando pela aprovação até a conclusão do Mestrado, foi um longo caminho percorrido. Nada foi fácil, nem tampouco tranquilo.

Quero agradecer a todos aqueles que sempre confiaram em mim, desde sempre. À Deus, minha família e minha Orientadora.

Aprendi que podemos sim depender das pessoas para que um sonho possa ser realizado. Para ser concluído o meu trabalho, foi necessária a ajuda de muitas pessoas. A frase "A união faz a força" nunca fez tanto sentido em minha vida como no mestrado, onde eu tanto precisei e tive ajuda de muitos. Sou extremamente grata por cada pessoa que se dedicou em me ajudar e que por tantas vezes foram minha mão esquerda. Vocês são demais e eu sou muito grata por tê-los em minha vida. Amanda Fernandes, Diego Martins, Isabel Weinhäuser, Leticia Marani, Maira Cacemiro, Thiago Bianco e todas as pessoas do laboratório de hematologia por terem sido tão solidários perante as minhas dificuldades

Aos meus pais, por me terem dado educação e valores. À minha mãe, amor incondicional. Mãe, você que me gerou e me alfabetizou, ensinando-me a ler, viu como aprendi direitinho? A vocês que, muitas vezes, renunciaram aos seus sonhos para que eu pudesse realizar o meu, partilho a alegria deste momento.

A todos os meus familiares, irmãs, sobrinhos Cecilia e Bernardo que são meus amores e fonte de toda minha inspiração. Se um dia pensei em desistir de tudo eles são a razão para eu continuar e ser exemplo para eles.

À Profa. ${ }^{a}$ Dra. Lorena Lobo de Figueiredo Pontes, minha orientadora e exemplo profissional e um exemplo de ser humano, obrigada por toda confiança e todo aprendizado nesses últimos anos. Quando 'crescer', eu quero ser como você.

Finalmente, a Fundação de Amparo à Pesquisa do Estado de São Paulo (FAPESP) pelo apoio financeiro concedido ao presente trabalho pelo processo no 2017/15484-4. 


\section{RESUMO}

Sanches, TP. Caracterização do nicho endosteal nas neoplasias mieloproliferativas associadas à mutação JAK2V617F. 2020. 43f. Dissertação (Mestrado em Ciências). Faculdade de Medicina de Ribeirão Preto, Universidade de São Paulo, Ribeirão Preto, 2020.

As Neoplasias Mieloproliferativas (NMPs) se originam de alterações moleculares ao nível da célula-tronco hematopoética (CTHS), mas alterações do nicho da medula óssea podem também contribuir para a regulação das funções das células-tronco neoplásicas e normais residuais e assim, participar da fisiopatologia da doença. Apesar das NMPs serem bem descritas, a contribuição do microambiente na doença foi pouco estudada. Dessa forma, é nosso objetivo estudar como as células do microambiente contribuem para a doença. Acreditamos que as NMPs se originem não apenas de defeitos intrínsecos da CTHS, mas também da sua regulação por um nicho anormal, capaz de dar suporte proliferativo à mielopoese. Sendo assim, objetivamos caracterizar fenotipicamente as células que dão suporte ao nicho hematopoético localizado no endósteo (células endoteliais, osteoblastos e célulasmesenquimais estromais) utilizando um modelo murino transgênico knockin de expressão heterozigótica condicional da mutação Jak2V617F. Para tanto, as células do nicho endosteal da medula óssea dos animais Jak2wt (controles) e Jak2VF (portadores de NMPs associada à mutação Jak2V617F) foram obtidas por meio de digestão dos fragmentos ósseos e caracterizadas por imunofenotipagem da MO total. Após exclusão de células hematopoéticas, as células do nicho foram identificadas como células endoteliais ( $\mathrm{CE}, \mathrm{CD} 31+/ \mathrm{Sca} 1+)$, células mesenquimais 
estromais (CM, CD31-/Sca-1+/CD51+) e Osteoblastos (OB, CD31-/Sca1-/CD51+). Os resultados deste trabalho possibilitaram estabelecer os métodos de isolamento de uma população pura de células mesenquimais no modelo transgênico Jak2V617F. Além disso, observamos diminuição dos osteoblastos nos animais Jak2VF em comparação aos controles Jak2wt. É possível que a deficiência numérica dos osteoblastos resulte em anormalidades funcionais no nicho que possam favorecer a expansão e/ou manutenção das células-tronco neoplásicas. Também não é possível excluir que as células-tronco neoplásicas exerçam um efeito supressor sobre o nicho, reduzindo subpopulações específicas do endósteo, sítio de importantes interações entre células-tronco e microambiente da medula óssea. Estas hipóteses geradas a partir de nossa caracterização fenotípica merecem esclarecimento por meio de estudos funcionais futuros.

Palavras-chave: Nicho endosteal; Mutação da JAK2; Neoplasias mieloproliferativas. 


\begin{abstract}
Sanches, TP. Characterization of the endosteal niche in myeloproliferative neoplasms associated to the Jak2V617F mutation. 2020. 43f. Dissertation (Master degree in Science). Ribeirao Preto Medical School, University of Sao Paulo, Ribeirao Preto, São Paulo, 2020.
\end{abstract}

Myeloproliferative neoplasms (MPN) originate from molecular changes at the hematopoietic stem cells (HSC) level, but changes in the bone marrow niche may also contribute to the functional regulation of neoplastic and normal residual stem cells, and thus participate in the pathophysiology of the disease. Although MPN are well described, the contribution of the microenvironment to the disease has not been fully studied. Therefore, it is our goal to study how the cells from the bone marrow microenvironment contribute to the disease. We believe that MPN are initiated not only by intrinsic HSC defects but also by its regulation by an abnormal niche, that provides proliferative support to myelopoiesis. Therefore, we aimed to phenotypically characterize cells that support the hematopoietic niche located at the endosteum (endothelial cells, osteoblasts and mesenchymal stromal cells) by the use of a murine transgenic knockin model of conditional heterozygous expression of the Jak2V617F mutation. For that, cells from the bone marrow niche of Jak2wt (controls) and Jak2VF (animals with Jak2V617F-associated MPN) were obtained by bone digestion and characterized by immunophenotyping of the total bone marrow. After exclusion of hematopoietic cells, the niche cells were identified as endothelial cells (EC, CD31+/Sca1+), mesenchymal stromal cells (MSC, CD31-/Sca-1+/CD51+) and osteoblasts (OB, CD31-/Sca1-/CD51+). Our results showed that it was possible to 
establish the methods for isolation of a pure population of mesenchimal stromal cells in the Jak2V617F transgenic model. In addition, we observed a decreased frequency of osteoblasts in the Jak2VF animals when compared to Jak2wt controls. It is possible that the numeric deficiency of osteoblasts results in functional abnormalities of the niche that may favor the expansion or maintenance of the neoplastic stem cells. It is also plausible that neoplastic stem cells exert a suppressive effect on the niche cells, thus reducing specific subpopulations of the endosteum, a site of important interactions between stem cells and the microenvironment of the bone marrow. Such hypotheses generated by our study deserve to be further explored by future functional studies.

Keywords: Endosteal niche; JAK2 mutation; Myeloproliferative Neoplasms. 


\section{LISTA DE ILUSTRAÇÕES}

Figura 1. Estratégia experimental de estudo do nicho da medula óssea do modelo transgênico Jak2 $v 617 f$

FIGURA2. Representação esquemática da geração do modelo transgênico knockin Jak2 $2_{v 617 f}$

Figura 3. . Estratégia de caracterização de células do nicho endosteal por imunofenotipagem 30

Figura 4 A. Ilustração da genotipagem para a presença do alelo vavCre no modelo murino JAK2V617F por meio de PCR de DNA genômico obtido do fragmento da orelha (gel de agarose $2,5 \%$ ).

Figura 4B. Comparação do tamanho do baço entre os animais Jak2VF (fenótipo de NMPS) e animais Jak2wt (controles)

Figura 4C. Comparação dos parâmetros hematimétricos dos animais Jak2VF (fenótipo de NMPS) e animais Jak2 wt (controles)

Figura 5. Estratégia de análise da imunofenotipagem de fluxo

Figura 6. Morfologia e imunofenotipagem das subpopulações do nicho hematopoético pelos métodos flushing e de digestão com colagenase 36

Figura 7. Frequência relativa e absoluta de células recuperadas da medula óssea de animais Jak2wt e Jak2VF por meio de flushing de ossos longos ou digestão de fragmentos ósseos com colagenase. 


\section{SUMÁRIO}

1. INTRODUÇÃO

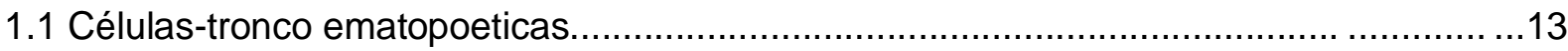

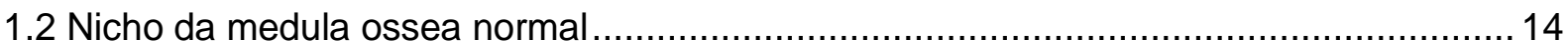

1.3 Neoplasias mieloproliferativas associadas à mutação da JAK2 …………………....... 18

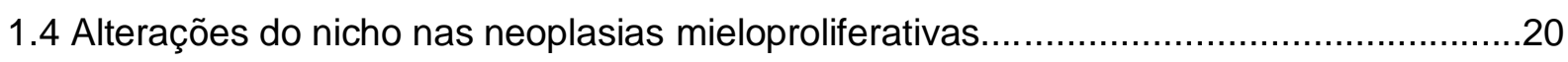

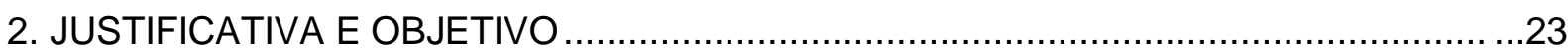

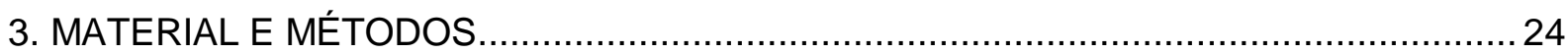

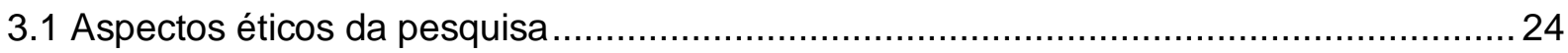

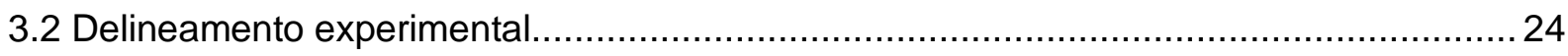

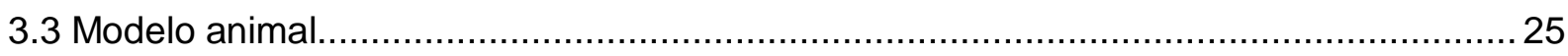

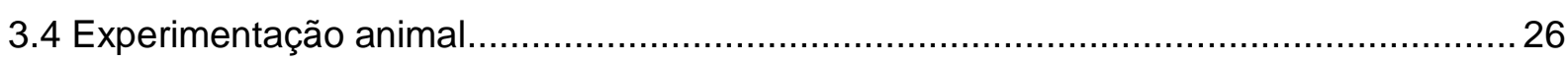

3.5 Isolamento de células mesenquimais pelo método de flushing para cultura..................27

3.6. Isolamento de células mesenquimais obtidas a partir da digestão dos fragmentos ósseos utilizando colagenase para cultura de longa duração …………………………........28

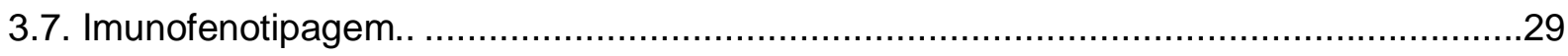

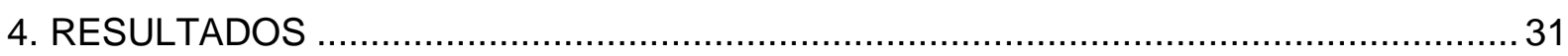

4.1 Caracterização genotípica e fenotípica dos animais portadores de NMPS associada à

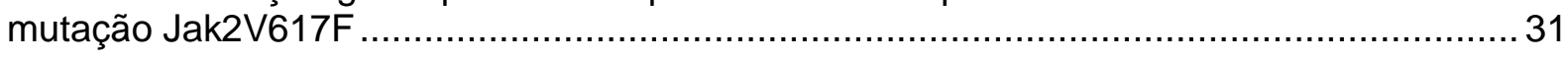

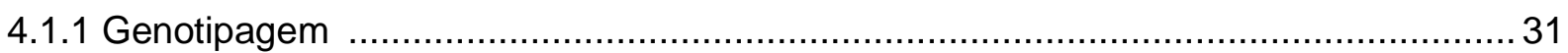

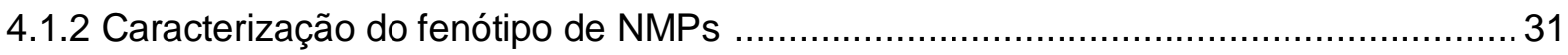

4.2. Padronização do isolamento das células mesenquimais............................................. 33

4.2.1 Avaliação da pureza de isolamento das células mesenquimais por meio de flushing

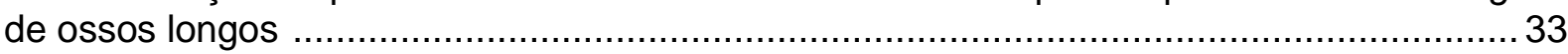

4.1.2 Avaliação da pureza de isolamento das células mesenquimais por meio de digestão de ossos longos com colagenase I

4.3 Avaliação da frequência dos componentes celulares do nicho endosteal em animais

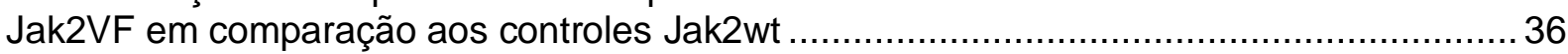

5. DISCUSSÃO

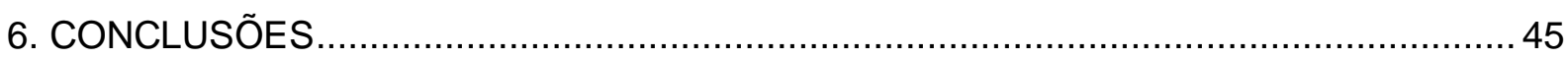

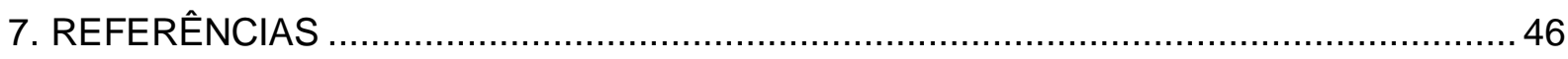

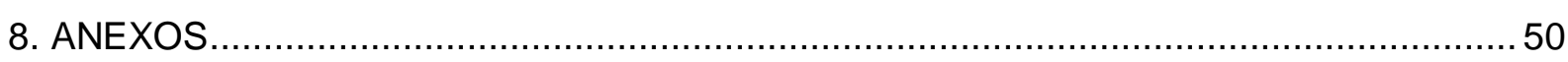

ANEXO - Parecer do Comitê de Ética em Animais ……...................................................51 


\section{INTRODUÇÃO}

\subsection{Células-tronco hematopoéticas}

Os diferentes tipos de células maduras do sangue originam-se a partir de células-tronco hematopoéticas (CTHs) presentes na medula óssea (MO). Essas células são as mais imaturas na hierarquia da diferenciação, sendo capazes de originar as linhagens eritroide, mieloide e linfoide (MÜLLER-SIEBURG et al., 2002; REYA et al., 2001). CTHs são capazes de reconstituir e manter o sistema hematopoético completo e funcional por longos períodos. Assim, são caracterizadas por três propriedades intrínsecas: capacidade proliferativa, pluripotencial (habilidade de diferenciação em todos os tipos de células sanguíneas) e capacidade de autorrenovação (FUCHS; TUMBAR; GUASCH, 2004; REYA et al., 2001). Esse potencial de autorrenovação ocorre por meio de divisão celular simétrica e assimétrica, ou seja, uma célula progenitora hematopoetica $(\mathrm{CPH})$ dá origem a duas células filhas, uma das quais permanece como célula-tronco pluripotente (divisão simétrica) e a outra migra para o compartimento principal da medula óssea, onde irá se diferenciar nas suas progênies (divisão assimétrica) (FUCHS; TUMBAR; GUASCH, 2004; REYA et al., 2001). Neste processo, duas subpopulações podem ser identificadas: CTHs com capacidade de autorrenovação a longo-termo (LTCTHS) e CTHs com capacidade de autorrenovação a curto termo (CT-CTHS). As LT-CTHs são capazes de se renovar indefinidamente, sendo responsáveis pela manutenção do pool de células hematopoéticas imaturas e indiferenciadas; enquanto as CT-CTHs são capazes de manter a hematopoese, originando-se de divisões celulares assimétricas da LT-CTHs, com maior potencial de proliferação e 
comprometimento para gerar os precursores das diferentes linhagens sanguíneas (MÜLLER-SIEBURG et al., 2002; WATT, 2000).

Em seres humanos adultos, as CTHs são responsáveis pela produção de $10^{9}$ glóbulos vermelhos e $10^{8}$ leucócitos em média, a cada hora, incluindo também plaquetas. (FUCHS; TUMBAR; GUASCH, 2004). As CTHs são provenientes da região embrionária aorta-gônada-mesonefros (AGM) e migram primeiro para a placenta e, depois, para fígado e baço fetais. Por volta da vigésima semana de vida intrauterina, a hematopoese passa a acontecer na $\mathrm{MO}$, onde a formação de células do sangue é mantida no período pós-natal (FUCHS; TUMBAR; GUASCH, 2004). Existe um equilíbrio rigorosamente preciso para regular a autorrenovação e diferenciação das CTHS, o qual depende de fatores intrínsecos e extrínsecos modulados pelo microambiente da MO (FUCHS; TUMBAR; GUASCH, 2004).

\subsection{Nicho da medula óssea normal}

O nicho da medula óssea consiste em uma unidade estrutural interativa composta por CTHs, precursores hematopoéticos e outros componentes celulares, fatores de crescimento, citocinas e proteínas de matriz extracelular, as quais favorecem a organização e a estrutura da MO (FUCHS; TUMBAR; GUASCH, 2004), e mantém o fenótipo final das CTHs, de forma a manter a homeostase do tecido (REYA et al., 2001). Esse nicho é definido por duas regiões com características distintas, denominadas de nicho osteoblástico (ou endosteal) e nicho vascular (PERRY; LI, 2007). O nicho endosteal é localizado na superfície interior da cavidade do osso, com abundante concentração celular de osteoblastos proporcionando um microambiente estável para as CTHs se manterem em estado quiescente (ARAI et al., 2004a; KONOPLEVA; JORDAN, 2011). O nicho vascular é localizado na região 
sinusoidal, próxima aos vasos sanguíneos, e, neste microambiente, as células recebem estímulos para promover a proliferação e diferenciação e são controladas pela proximidade das células endoteliais (CEs), células mesenquimais (CMs) e megacariócitos (KONOPLEVA; JORDAN, 2011; ZHANG et al., 2003).

Sabe-se que o funcionamento normal das CTHs é dependente de um programa rigoroso de regulação da sua quiescência, autorrenovação e diferenciação (KONOPLEVA; JORDAN, 2011; PARK, 2012). Fatores de crescimento, citocinas e proteínas da matriz extracelular são produzidas pelas células do nicho hematopoético, dando suporte essencial para a manutenção a longo prazo de um pool estável de CTHs (SCADDEN, 2007).

As células do nicho dito endosteal são representadas por células endoteliais (CEs), osteoblastos (OBs) e células mesenquimais (CMs).

Com base em estudos in vivo e ex vivo, as CEs da medula óssea expressam fatores que promovem hematopoese, como o fator estimulador de colônias de granulócitos (G-CSF), fator estimulador de colônias de granulócitos e macrófagos (GM-CSF), fator estimulador de colônias de macrófagos (M-CSF), fator de célulastronco (SCF; também conhecido como ligante KIT), interleucina-6 (IL-6) e ligante de tirosina quinase 3 está relacionada com FLT3 (FLT3L; também conhecido como ligante FLK2) (YODER et al., 2007). Além disso, foi demonstrado que essas células expressam as moléculas de adesão E-selectina, P-selectina, molécula de adesão celular 1 (VCAM1) e molécula de adesão intercelular 1 (ICAM1). A vasculatura da medula óssea é heterogênea, e apresenta aumento da expressão das moléculas do nicho tais como a E-selectina e o motivo ligante C-X-C 12 (CXCL12), as quais facilitam o retorno das CTHs para a medula óssea. Essas vias de retorno são exploradas por doenças malignas que podem invadir a medula óssea (BUTLER et 
al., 2010; KOBAYASHI et al., 2010; TEOFILI et al., 2011, 2011). In vitro, CEs imortalizadas podem dar suporte à função da CTHs em cultura por meio da expressão de ligantes Notch (MÉNDEZ-FERRER et al., 2010a). Da mesma forma, a expressão de uma forma mutante constitutivamente ativa de AKT em células endoteliais, usando um modelo de camundongo transgênico condicional específico de células endoteliais, leva a um aumento nos números de CTHs (MORRISON; SCADDEN, 2014). Essas características sustentam a ideia de que as CEs podem fornecer funções às células hematopoéticas in vivo, embora a evidência conclusiva de que eles o façam ainda não esteja disponível.

As CEs são cercadas por células mesenquimais (CMs) perivasculares, que fornecem o suporte estrutural e abrigam populações de células que podem regenerar o estroma da medula óssea e interagir diretamente com as CTHs. Uma subpopulação de CMs da medula óssea que é caracterizada pela expressão do marcador de superfície CD146 em humanos (OMATSU et al., 2010) ou da proteína de filamento citoplasmático nestina em camundongos (OMATSU et al., 2010), pode dar origem a microambientes hematopoéticos ectópicos após o transplante, sugerindo que essas células estão envolvidas na regeneração do estroma da medula óssea. Essas células envolvem os vasos sanguíneos e as fibras nervosas adrenérgicas, tanto na região central quanto na endosteal da medula óssea, e expressam várias proteínas que regulam a manutenção das CTHs, incluindo CXCL12, angiopoietina-1 e SCF. A exclusão de CMs que expressam nestina leva a uma redução de 50\% nos números de CTHs da medula óssea havendo um aumento proporcional nos números de CTHs no baço, sugerindo que as células que expressam nestina estão envolvidas na fixação de CTHs em um local perivascular dentro da medula óssea (WALKLEY et al., 2007). 
Existem funções distintas para vários tipos de populações de células CMs que estão em processo de definição. Por exemplo, dados recentes sugerem que células mesenquimais mais primitivas, como aquelas que expressam nestina, participam da regulação das CTHs (VALTIERI; SORRENTINO, 2008). As CMs representam uma população de células multipotentes, capazes de se diferenciar e produzir qualquer tipo celular necessário para um processo de reparação, como osteoblastos, condroblastos, hepatócitos, neurônios, células epiteliais, renais, cardíacas (SCHOFIELD, 1978). Na MO, regulam o microambiente controlando a quiescência e a proliferação das CTHs (KASTRINAKI et al., 2013) e também têm importantes efeitos imunossupressores (MAJUMDAR et al., 2000; MAURO; O'DWYER; DRUKER, 2001a). Embora vários estudos tenham investigado a importância das CMs no nicho hematopoético, este papel não está totalmente esclarecido (PRASANNA et al., 2010). Sabe-se que estas células expressam uma grande variedade de receptores para quimiocinas e fatores de crescimento (ARAl et al., 2004b; PETIT et al., 2002) e que, em diversas doenças com anormalidades na MO ocorre desregulação da expressão de citocinas ou quimiocinas como IFN- $\gamma$, TNF- $\alpha$, IL-1 $\beta$, ou IL-6 que podem afetar de forma diferenciada os vários componentes celulares da MO.

Os osteoblastos (OBs) são células derivadas das CMs e secretam fatores que regulam a manutenção das CTHs, incluindo angiopoetina, trombopoetina e CXCL12 (KIEL et al., 2005; SOTIROPOULOU; PAPAMICHAIL, 2007). Estudos funcionais indicam que a angiopoetina e trombopoetina promovem quiescência das CTHs, ao passo que CXCL12 regula a migração e localização destas células na MO (KIEL et al., 2005; SOTIROPOULOU; PAPAMICHAIL, 2007). As CTHs em condições normais encontram-se localizadas próximas aos osteoblastos endosteais. Tal 
proximidade física sugere que há interação entre CTHs e OBs. De fato, demonstrouse que CTHs murinas definidas como linhagem negativas (-), Sca1+, cKit+, CD48-, CD150+ isoladas de regiões endosteais do fêmur têm maior potencial de reconstituição hematopoética a longo prazo do que células fenotipicamente idênticas isoladas da MO central (WANG et al., 2013). As células hematopoéticas mais imaturas estão localizadas ao longo da superfície endosteal, com um gradiente de diferenciação movendo-se em direção ao eixo central da cavidade medular para a região perivascular (MAURO; O'DWYER; DRUKER, 2001b; WANG et al., 2013).

\subsection{Neoplasias mieloproliferativas associadas à mutação da JAK2.}

As neoplasias hematopoéticas se originam de alterações genéticas moleculares ao nível da CTHs, mas alterações do nicho podem contribuir para a regulação das funções das células-tronco neoplásicas e das CTHs normais residuais e, assim, participar da fisiopatologia da doença. Conforme classificado pela Organização Mundial de Saúde (OMS) em 2016 (GRIESINGER et al., 2005; ZHANG et al., 2003), dentre as chamadas neoplasias mieloides estão: as leucemia mieloide crônica (LMC, BCR-ABL1 postiva), leucemia neutrofílica crônica, leucemia eosinofílica crônica, policitemia vera (PV), trombocitemia essencial (TE), mielofibrose primária (MFP), mastocitose e NMPs inclassificáveis que são categorizadas como NMPs BCR-ABL1 negativas. Dentre essas, as NMPs clássicas são PV, TE e MFP, que consistem um grupo heterogêneo de doenças hematopoéticas clonais caracterizadas pela produção excessiva de uma ou mais linhagens de células maduras do sangue (linhagens eritroide, mieloide e/ou megacariocítica), e levam a complicações clínicas como esplenomegalia decorrente da hematopoese extramedular, eventos trombóticos, hemorragia e potencial evolução para 
mielofibrose secundaria ou para leucemia mieloide aguda (LMA) (MAURO; O'DWYER; DRUKER, 2001a).

Em 2005, vários estudos clínicos relacionaram a ocorrência de mutações no gene da Janus Quinase 2 (JAK2), localizado no cromossomo 9. Destaca-se a descoberta da mutação pontual JAK2V617F como um fator para o desenvolvimento de algumas destas doenças (BAXTER et al., 2005). Esta mutação, localizada no éxon 14 do gene JAK2 ocorre por substituição de uma guanina por timidina resultando na substituição de uma valina por uma fenilalanina que ocorre na posição 617 da proteína. Demonstrou-se que a substituição na proteína ocorre no domínio inibitório da mesma e provoca a ativação constitutiva da atividade tirosina-quinase localizada na porção intercitoplasmática de receptores dos fatores de crescimento como eritropoetina, fator estimulante de colônia de granulócitos (G-CSG) e trombopoetina, aumentando a sensibilidade à ação destes ligantes ou desencadeando ativação autônoma da via de sinalização JAK/STAT (KRALOVICS et al., 2005; VAINCHENKER; KRALOVICS, 2017).

As mutações ditas fenotípicas, ou seja, que determinam o fenótipo de proliferação mieloide característico das NMPs, são mutuamente exclusivas resultam na ativação da via JAK/STAT e, consequentemente, em sinais intracelulares que aumentam a proliferação e reduzem a morte celular. A mais clássica delas consiste na mutação somática JAK2V617F, que pode ser identificada em cerca de 96\% dos casos de PV, e em aproximadamente 50 a $60 \%$ dos pacientes com TE e MFP. Nos casos de TE e MFP negativos para a mutação da JAK2, mutações somáticas no éxon 10 do receptor da trombopoetina MPL (MPLW515L/K/A/R/G) podem ser observadas em aproximadamente 5 a 10\% dos pacientes, e mutações no éxon 9 da calreticulina (CALR) em 20 a 25\% dos casos (CALVI et al., 2003). 
Em adição às mutações oncogênicas, outras anormalidades podem ser observadas nas NMPs, tais como demonstram as evidências de contribuição do microambiente da MO na patogênese das neoplasias mieloides. De fato, as alterações no microambiente, tais como aumento da densidade microvascular (angiogênese), fibrose e espessamento das trabéculas ósseas (ARBER et al., 2016, 2016; GRIESINGER et al., 2005; WANG et al., 2013; ZHANG et al., 2003).

\subsection{Alterações do nicho nas neoplasias mieloproliferativas}

Há evidências de que o nicho hematopoético influencia na proliferação, sobrevivência e migração de células-tronco leucêmicas. Alterações observadas no nicho em neoplasias mieloides sugerem que este parece sofrer uma modulação secundária à transformação clonal das CTHs e células-tronco progenitoras nas NMPs (BAXTER et al., 2005; GRIESINGER et al., 2005; MAURO; O'DWYER; DRUKER, 2001b). Estudos experimentais realizados em um modelo de camundongos transgênicos de LMC em fase crônica sugeriram que as células mieloides leucêmicas remodelam o nicho endosteal da MO. Observou-se que no nicho leucêmico do modelo de LMC, os OBs encontram-se com a sua função alterada, prejudicando a hematopoese normal, favorecendo a função das célulastronco neoplásicas e contribuindo para o desenvolvimento de fibrose da MO. (VAINCHENKER; KRALOVICS, 2017) Utilizando um modelo murino de LMC induzida por BCR-ABL (modelo murino SCL-tTA/TRE-BCR/ABL), Schepers e colaboradores mostraram que as células leucêmicas estimularam a produção excessiva de células osteoblásticas que, por sua vez, apresentavam expressão reduzida de fatores como integrina e caderina, importantes para regulação da família IL-1 de citocinas pró-inflamatórias que contribuem para manutenção das CTHs, 
resultando assim em capacidade diminuída para dar suporte às CTHs normais. Em células osteoblásticas anormais, detectou-se aumento da expressão de genes relacionados à inflamação e à mielofibrose, sugerindo que estas células podem contribuir para a fibrose da medula óssea (BAXTER et al., 2005; VAINCHENKER; KRALOVICS, 2017). Outro estudo mostrou que defeitos osteoblásticos graves foram encontrados em um modelo $B C R-A B L / N u p 98 / H o x A 9$, no qual osteoprogenitores, osteoblastos endosteais e a massa óssea encontravam-se diminuídos e com maior expressão de CCL3 (KRALOVICS et al., 2005; VAINCHENKER; KRALOVICS, 2017).

Sabe-se que alterações no microambiente da medula óssea como aumento da densidade microvascular, fibrose e expressão aberrante de citocinas inflamatórias contribuem para o fenótipo das NMPs. Acredita-se que tanto as células-tronco progenitoras como megacariócitos e monócitos secretam citocinas como IL-6, IL-8, VEGF, FGF, PDGF, TNFa, TGF $\beta$, oncostatina M e SDF-1 (CXCL12). Estas citocinas se ligam aos seus receptores em células endoteliais, fibroblastos e células do estroma da medula óssea e podem induzir fibrose e angiogênese em maior ou menor grau (KRALOVICS et al., 2005; KRAUSE; SCADDEN; PREFFER, 2013b).

Uma das grandes características da malignidade é a presença da inflamação (KRAUSE; SCADDEN; PREFFER, 2013a), (SCHMITT-GRAEFF; NITSCHKE; ZEISER, 2015), que é reconhecida como um importante fator na patogênese das síndromes mielodisplásticas (SMD) e leucemia mieloide aguda (LMA), e envolve diferentes vias de sinalização celulares e moleculares (16, (SCHEPERS et al., 2013a). Assim, o estado contínuo de inflamação provido pelo nicho leucêmico pode contribuir para a iniciação e progressão das doenças hematológicas. A reação do estroma, por sua vez, pode amplificar as alterações 
mieloproliferativas contribuindo para a progressão da doença. (MAJUMDAR et al., 2000)

Ainda são desconhecidos os mecanismos exatos pelos quais a hematopoese mieloproliferativa anormal tem impacto sobre o microambiente da medula óssea. Embora estudos recentes tenham corroborado para elucidação dos mecanismos de contribuição de algumas células do nicho em LMC, pouco se sabe a respeito dessa contribuição nas NMPs BCR-ABL1 negativas. Acreditamos que o fenótipo e função das células do nicho das NMPs sejam anormais e que, além de contribuírem para a mielofibrose, levem à amplificação das anormalidades das células-tronco que iniciam e mantém a doença. De maneira recíproca, as neoplasias mieloides também afetam a função do microambiente da medula podendo prejudicar a hematopoese normal, favorecendo a expansão maligna das células-tronco. As CMs de pacientes com neoplasias hematológicas podem ser comprometidas e apresentarem funções desreguladas (PELED, 1999; YOSHIHARA et al., 2007). 


\section{JUSTIFICATIVA E OBJETIVO}

As Neoplasias Mieloproliferativas (NMPs) se originam de alterações clonais ao nível da célula-tronco hematopoética (CTHs). Entretanto, estas alterações não são suficientes para explicar completamente a fisiopatologia e determinar os diferentes fenótipos desse grupo de doenças. Se, por um lado, a desregulação do microambiente pode contribuir para a transformação neoplásica ao modular as propriedades da CTHs, por outro, a hematopoese leucêmica das NMPs também pode modificar o microambiente. As anormalidades do microambiente da medula óssea (MO) nas NMPs não estão completamente esclarecidas. A maior parte das evidências deriva de modelos de mielofibrose, nos quais as alterações mediadas por citocinas resultam na fibrose da $\mathrm{MO}$, um evento tardio na evolução das NMPs. Pouco se sabe sobre alterações mais precoces que podem ocorrer na PV, TE ou nas fases pré-fibróticas da mielofibrose. Diante disso, e do conhecimento da proximidade física e potencial interação entre CTHs e nicho endosteal, almejamos caracterizar fenotipicamente as células do nicho endosteal com objetivo de contribuir para a investigação da potencial regulação das CTHs pelo nicho neoplásico nas NMPs associadas à mutação da JAK2.

\section{Objetivo}

Isolar e caracterizar as células que compõem o nicho endosteal da medula óssea, sendo elas células mesenquimais (CMs), Osteoblastos (OBs) e células endoteliais (CEs) em doenças mieloproliferativas usando como ferramenta o modelo murino transgênico knockin JAK2V617F. 


\section{MATERIAL E MÉTODOS}

\subsection{Aspectos éticos da pesquisa}

O projeto de pesquisa foi aprovado pela Comissão de Ética no Uso de Animais do Hemocentro da Faculdade de Medicina de Ribeirão Preto - USP (Parecer CEUA número 172/2017, em anexo).

\subsection{Delineamento experimental}

O algoritmo apresentado na Figura 1 resume a estratégia experimental do estudo, que inclui a padronização do isolamento de células mesenquimais em cultura de longa duração bem como a caracterização das subpopulações do nicho da medula óssea do modelo transgênico de neoplasia mieloproliferativa (NMPS) associado à mutação Jak2V617F.

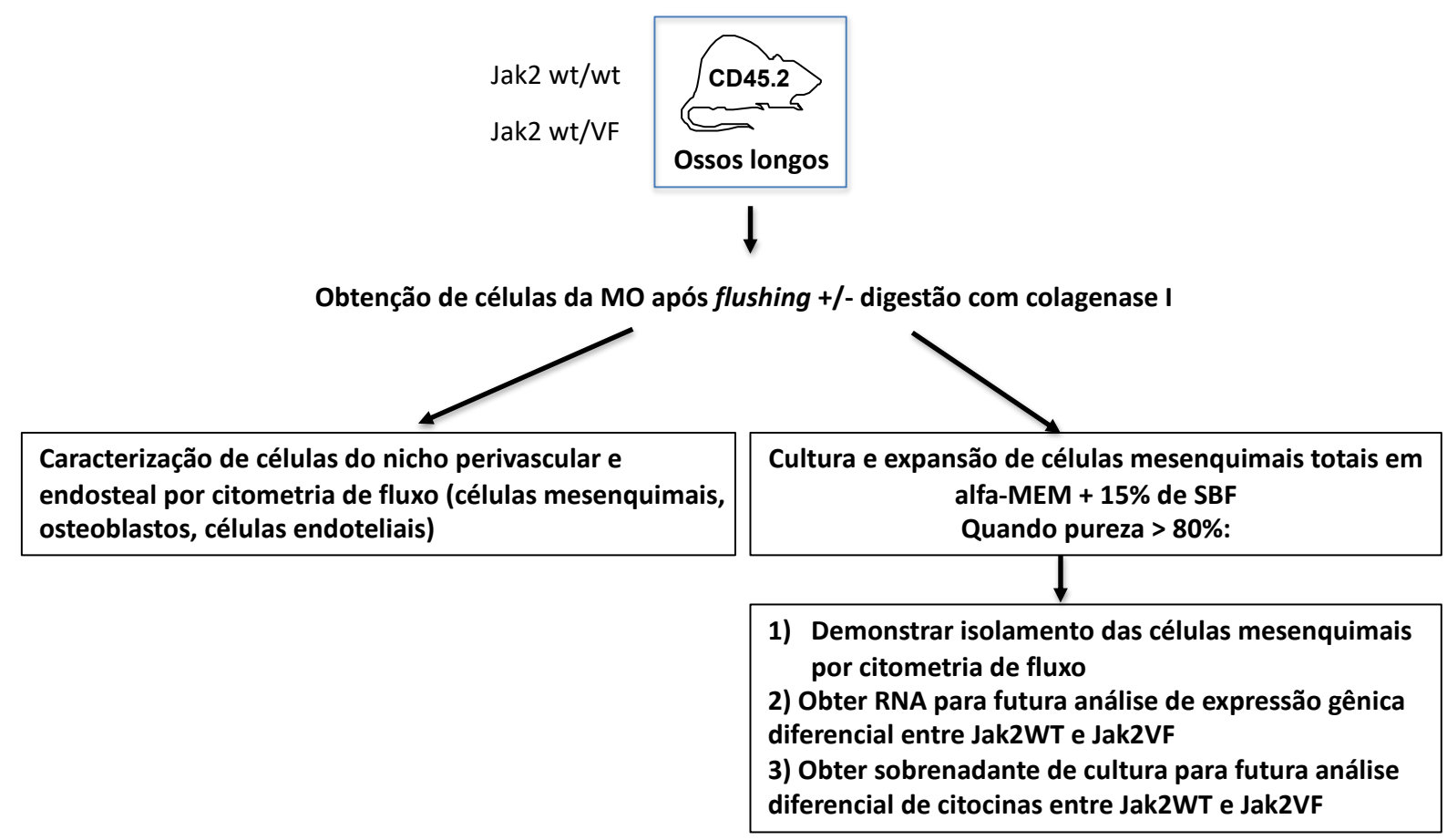

Figura 1. Estratégia experimental de estudo do nicho da medula óssea do modelo transgênico Jak2V617F. 


\subsection{Modelo animal}

Foi utilizado, como modelo de neoplasia mieloproliferativa (NMPs), camundongos C57/BL6 transgênicos vavCre e Jak2wt/V617F (todos C57BL/6 com background CD45.2). As colônias Jak2 e vavCre foram mantidas no Laboratório de Estudos Experimentais em Animais (LEEA) do Hemocentro - FMRP-USP, sob condições livre de patógenos e mantidas de acordo com as políticas do Comitê de Ética em Pesquisa em animais. Os detalhes da geração do modelo knockin para a mutação Jak2V617F estão disponíveis na literatura (PRASANNA et al., 2010) . Os camundongos expressam a mutação Jak2V617F de forma heterozigótica, sendo que os animais Jak2 wt/FI são portadores, mas não expressam o fenótipo clínico da doença. $O$ acasalamento destes animais heterozigotos com animais transgênicos vavCre, resulta na expressão germinativa da mutação Jak2V617F em todas as células hematopoéticas bem como células endoteliais dos animais transgênicos. A recombinação Cre ocorre em duas etapas, uma que remove o éxon wt (do inglês, wild-type) e a outra que coloca o éxon V617F na orientação certa para que ocorra a transcrição. Os animais JAK2 wt/FI vavCre positivos (denominados a partir deste ponto de Jak2VF) expressam a Jak2 mutada (V617F) e desenvolvem NMPs letal com $100 \%$ de penetrância a partir de quatro semanas de vida, com sobrevida média de 100-150 dias, caracterizada por elevação do hematócrito, leucocitose, esplenomegalia e eritropoese extramedular proeminente, muito semelhante à policitemia vera (PV) humana. Os animais considerados controles são camundongos Jak2 wt/wt vavCre positivos (ou Jak2wt). 


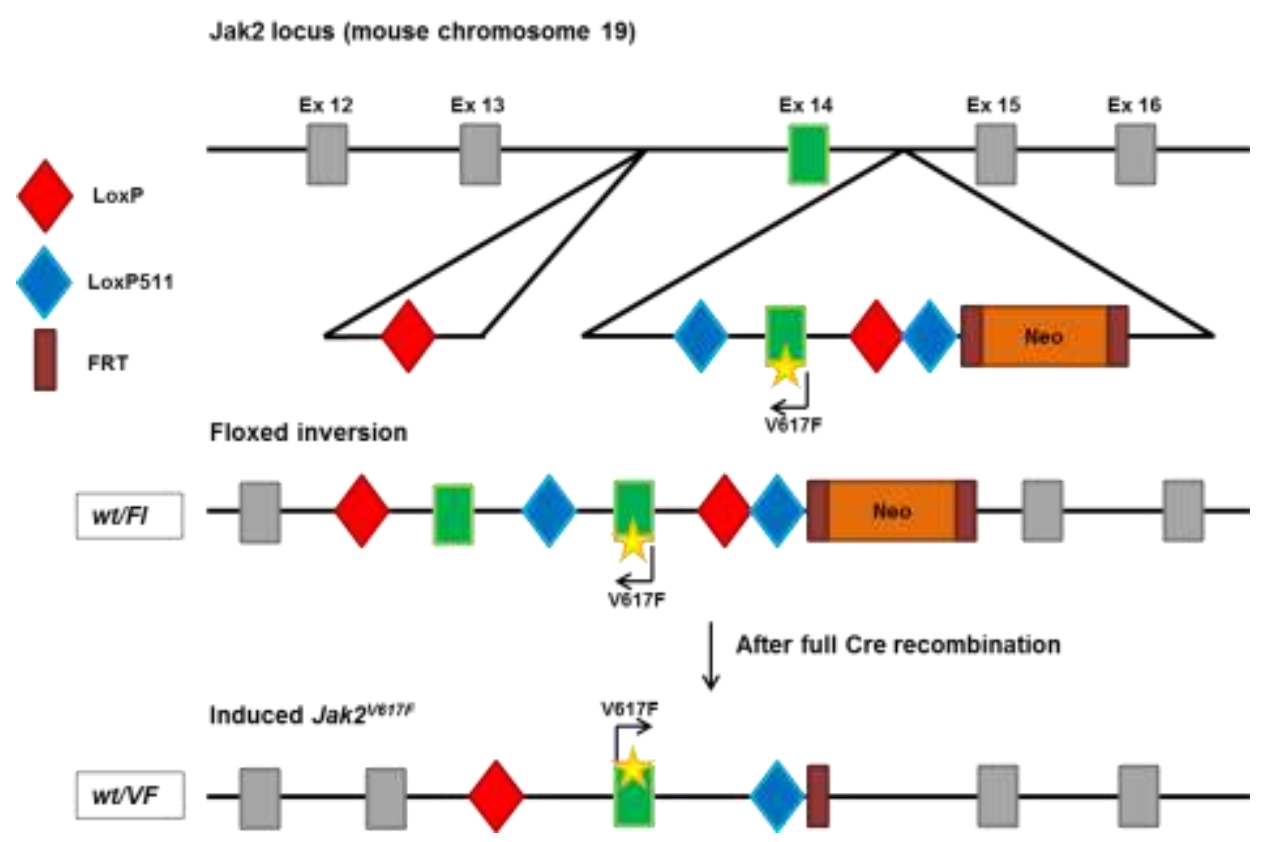

Figura 2. Representação esquemática da geração do modelo transgênico knockin Jak2V617F. Inicialmente, um sítio LoxP foi introduzido anteriormente ao éxon 14 normal da Jak2 e, em seguida, um cassete de clonagem consistindo nas seguintes regiões: um sítio LoxP511, o fragmento de cDNA numa orientação invertida contendo a mutação G1849T (que resulta na troca de aminoácidos V617F), um sítio LoxP (Fonte: Adaptado de Mullally A. et al., Physiological Jak2V617F expression causes a lethal myeloproliferative neoplasm with differential effects on hematopoietic stem and progenitor cells. Cancer Cell. 2010 Jun 15;17(6):584-596).

\subsection{Experimentação animal}

Os animais da colônia JAK2 foram selecionados para a experimentação de acordo com a genotipagem, sendo utilizados animais controles (Jak2wt) e portadores de NMPs associada à mutação Jak2V617F (Jak2VF), com idade entre 8 e 12 semanas, num total de 5 animais por grupo para cada comparação realizada (isolamento de células mesenquimais totais e quantificação de subpopulações do nicho). O fenótipo dos animais quanto à realização de hemograma do sangue periférico e tamanho/peso do baço foram sempre observados. Os animais foram eutanasiados com sobredose intraperitoneal de 2,2,2-Tribromoethanol (Sigma Aldrich), seguida de descolamento cervical, de acordo com as recomendações éticas da Instituição. 


\subsection{Isolamento de células mesenquimais pelo método de flushing para cultura}

Inicialmente, o isolamento de células mesenquimais do nicho hematopoético foi realizado pela técnica de flushing, conforme se detalha a seguir.

Após a eutanásia dos animais Jak2VF e Jak2wt, os ossos longos das 4 patas foram excisados e limpos de tecido muscular e ligamentos, as epífises cortadas e com auxílio de agulha $24 \mathrm{G}$, os ossos foram submetidos ao flushing com $5 \mathrm{~mL}$ de solução salina tamponada (PBS, do inglês phosphate-buffered saline). Por este método, obtém-se tanto células hematopoéticas como células do estroma da medula óssea (em menor quantidade) inicialmente e, apenas após o cultivo com remoção das células não aderentes, é possível isolar células do nicho após várias passagens. As células provenientes desta lavagem inicial foram contadas em câmara de Neubauer, distribuídas em placas de Petri de $25 \mathrm{~mm}$ ou garrafas de $25 \mathrm{~cm}^{2}$, cultivadas em meio DMEM (Gibco) com $15 \%$ de soro bovino fetal (SFB, Gibco), gentamicina $50 \mu \mathrm{g} / \mathrm{mL}$ (Nova Farma), em estufa a $37^{\circ} \mathrm{C}$ com $5 \%$ de $\mathrm{CO}_{2}$ por 3 horas. Após as três primeiras horas de cultivo, as células sobrenadantes não aderentes, que se acumulam no meio da superfície da placa, foram retiradas e substituídas por um meio completo fresco. Depois, foram incubadas por mais dezoito horas, repetindo-se o procedimento de retirada do meio de cultura contendo células não aderentes e adição de novo meio. Este procedimento foi repetido por mais 72 horas (Dia 1 ao Dia 3 ). No terceiro dia, o meio foi completamente retirado e procedeu-se à lavagem cuidadosa com PBS 1X, seguida da adição de meio DMEM com $15 \%$ de SBF fresco. Esta troca de meio com lavagem foi repetida por mais 16 dias. 


\subsection{Isolamento de células mesenquimais obtidas a partir da digestão dos fragmentos ósseos utilizando colagenase para cultura de longa duração}

$\mathrm{O}$ isolamento das células mesenquimais foi realizado de acordo com 0 protocolo estabelecido por Zhu e colaboradores (ZHU et al., 2010). Resumidamente, após a eutanásia, os ossos longos das cinco patas foram excisados e limpos de tecido muscular e ligamentos, as epífises cortadas, e com auxílio de agulha 24G, os ossos foram submetidos ao flushing com $5 \mathrm{~mL}$ de PBS, de forma a remover a maioria das células hematopoéticas. Após a lavagem completa, os ossos foram cortados em pequenos pedaços de cerca de $0,1 \mathrm{~cm} \times 0,1 \mathrm{~cm}$ (aproximadamente $9 \mathrm{a}$ 10 fragmentos por poço) e colocados em meio alfa-MEM (Gibco) com $1 \mathrm{mg} / \mathrm{mL}$ colagenase tipo I (Worthington Biochemical) por 2 horas a $37^{\circ} \mathrm{C}$ sob agitação. Por este método, descarta-se a maioria das células hematopoéticas no flushing e digerese os ossos com colagenase para obter as células do estroma da medula óssea.

Após a digestão, os fragmentos ósseos foram transferidos para garrafas de cultura de $25 \mathrm{~cm}^{2}$ com meio alfa-MEM suplementados com $15 \%$ de SBF, gentamicina $50 \mu \mathrm{g} / \mathrm{mL}$ (Nova Farma) e anfotericina B $25 \mu \mathrm{g} / \mathrm{mL}$ (Invitrogen), e mantidos em cultura a $37^{\circ} \mathrm{C}$ e $5 \%$ de $\mathrm{CO} 2$. Após três dias de cultura, o meio foi trocado e as células do sobrenadante foram descartadas, um novo meio foi adicionado e a cultura mantida por cinco dias. Após esse período, o meio foi trocado a cada 48 horas e, quando a garrafa atingiu $80 \%$ de confluência das células aderentes, o conteúdo foi repicado utilizando $0,25 \%$ de tripsina-EDTA (Thermo Fisher Scientific). A cada repique foi considerada uma passagem e, quando as células atingiram a passagem cinco (P5), as mesmas foram utilizadas para a caracterização por imunofenotipagem. Após repetições do método para otimização, 
confirmamos 0 isolamento de células mesenquimais (CMs) por meio de imunofenotipagem,

\subsection{Imunofenotipagem}

Para avaliação inicial do isolamento de células do nicho da medula óssea, e comparação entre os dois métodos de isolamento descritos anteriormente, utilizamos estratégia de análise baseada na detecção dos seguintes marcadores: CD45.2, F4-80, CD11b, CD34 e CD135.

Após a padronização do isolamento de células do nicho por meio de digestão com colagenase I, procedemos à identificação mais detalhada de células do nicho endosteal, conforme descrição da literatura (Figura 2)(SCHEPERS et al., 2013a). O conteúdo da digestão dos fragmentos ósseos com colagenase I foi submetido à imunofenotipagem para caracterização do nicho endosteal. A estratégia para caracterização a partir da gate inicial por tamanho e granulosidade (SSC x FSC) incluiu a exclusão de células hematopoéticas (incluindo marcadores de células $B, T$ e eritroides, além do marcador pan-hematopoético CD45), utilizando coquetel denominado linhagem negativo (Lin-) que incluiu os seguintes marcadores: CD3, CD19, TER119, CD45, de forma a selecionar a população negativa para a marcação descrita. Adicionalmente, as células foram marcadas com os seguintes anticorpos conjugados: CD31-PE/Cy7, CD51-PE e Sca-1-APC (todos da marca Biolegend®) e plotadas de forma a selecionar as subpopulações esperadas, ou seja, células endoteliais, células mesenquimais estromais e osteoblastos. A aquisição das amostras foi realizada no citômetro de fluxo FACS Canto II (BD Biosciences ${ }^{\mathrm{R}}$, San Diego, USA), e as análises foram realizadas utilizando o software FlowJo V10. 


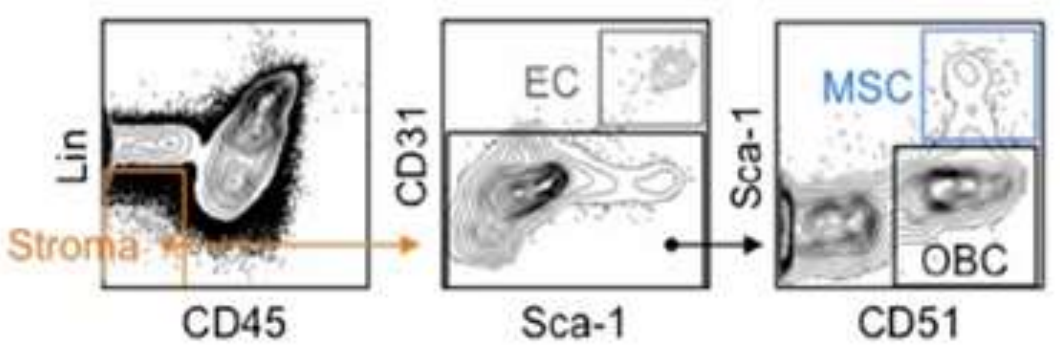

Figura 3. Estratégia de caracterização de células do nicho endosteal por imunofenotipagem. EC: células endoteliais; MSC: células mesenquimais estromais; OBC: osteoblastos. Fonte: SCHEPERS, K. e colaboradores (SCHEPERS et al., 2013b) . 


\section{RESULTADOS}

\subsection{Caracterização genotípica e fenotípica dos animais portadores de NMPS associada à mutação Jak2V617F}

\subsubsection{Genotipagem}

Os animais da colônia de animais transgênicos Jak2V617F foram selecionados para a experimentação de acordo com a genotipagem, que permite identificar animais controles (Jak2wt) e portadores de NMPs (Jak2VF). O DNA genômico dos animais após a quarta semana de vida foi obtido a partir de pequenos fragmentos da orelha dos camundongos, e foi realizada genotipagem por meio da técnica de Reação em Cadeia de Polimerase (PCR) com oligonucleotídeos específicos para a amplificação da Jak2 wt e mutada, bem como para a presença da enzima cre-recombinase. Foram utilizados os seguintes reagentes para a reação de PCR: Taq 5U/ $\mu \mathrm{L}$ (Promega GO Taq DNA Polymerase), Buffer 5X ( $\left.\mathrm{MgCl}_{2}-1.5 \mathrm{mM}\right)$, desoxirribonucleotídeos fosfatados (dNTPs $1.25 \mu \mathrm{M}$ cada) e os oligonucleotídeos (Jak2.Fw, Jak2.Rv, vavCre.Fw e vavCre.Rv) na concentração de $10 \mu \mathrm{M}$. As reações foram realizadas no termociclador Veritiß 96-Well Thermal Cycler (Applied Biosciences, Foster City, CA, EUA).

A análise genotípica Jak2 e vavCre foi finalmente determinada por meio de eletroforese em gel de agarose 2,5\%. Os animais portadores de NMPS (Jak2VF) apresentam duas bandas (250 pb e 350 pb), enquanto que os animais controles (Jak2wt) apresentam apenas a banda de tamanho de 250 pb (Figura 4A). 


\subsubsection{Caracterização do fenótipo de NMPs}

Uma característica clínica das NMPs é o aumento no tamanho do baço (esplenomegalia), que foi observado nos animais Jak2VF analisados em comparação aos animais Jak2wt (Figura 4B). Além disso, observou-se contagens aumentadas de glóbulos vermelhos, leucócitos e plaquetas bem como elevação da hemoglobina e hematócrito nos animais Jak2VF em comparação aos animais Jak2wt (Figura 4C).

A)

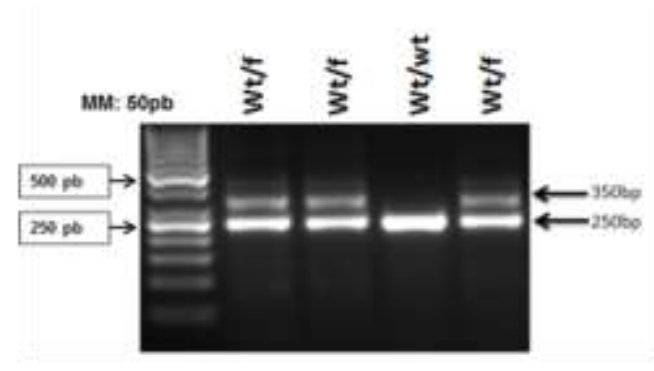

C)

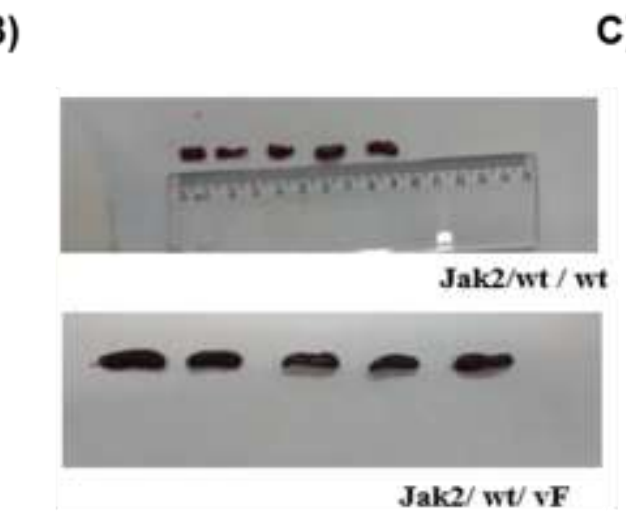

\begin{tabular}{|c|c|c|c|c|c|}
\hline Animais & GV & HGB & HCT & GB & PLAQTS \\
\hline 1. 190 wtllft & $14.1910^{\circ \mathrm{mmi}}$ & $21.3 \mathrm{gld}$ & $64.0 \%$ & $9.710^{1 \mathrm{mal}}$ & $2471103 \mathrm{~mm} 3$ \\
\hline 2- J111 wt lf* & $16.5210^{5 \mathrm{~mm}} \mathrm{I}$ & $23.9 \mathrm{~g} \backslash \mathrm{dl}$ & $75.2 \%$ & $1110^{3 \mathrm{~mm}}$ & $279110^{3 \mathrm{~mm}}$ \\
\hline $3-115$ wt $f_{+}$ & $14.3010^{\mathrm{mmens}}$ & $20.7 \mathrm{~g} \backslash \mathrm{dl}$ & $65 \%$ & $11.310^{\mathrm{mmm}}$ & $201610^{\mathrm{pm} m \mathrm{mes}}$ \\
\hline 4- 1116 wtlf* & $1498106^{\mathrm{ran}}$ & $13.7 \mathrm{~g}$ del & $39.7 \%$ & $\begin{array}{c}10.4106 \mathrm{mms} \\
1869103\end{array}$ & $10.010^{\text {nnma }}$ \\
\hline 5- J128 wetfft & $8.30106^{\mathrm{mm}}$ & $13.8 \mathrm{~g} \backslash \mathrm{dl}$ & $39.8 \%$ & $10.010^{\mathrm{inn} a}$ & $51110^{n / m m a}$ \\
\hline 6- 1129 wtlwt+ & 8.31109 onent & $13,7 \mathrm{e} \backslash \mathrm{dl}$ & $39.7 \%$ & $\begin{array}{c}10,410 \text { innd } \\
344103 \backslash \mathrm{mm}^{3}\end{array}$ & 343\mm3 \\
\hline 7. J141 wtlwtt+ & $16.5210^{\mathrm{s} / \mathrm{mm}}$ & 23.9gldl & $75.2 \%$ & $6.01^{\cos / \mathrm{mm}}$ & 2791 10 \\
\hline 8- J142 wt lwt + & $9.07100 \mathrm{~mm}$ & $14.9 \mathrm{~g} \backslash \mathrm{dl}$ & $43.8 \%$ & $6.054010^{\mathrm{r} / \mathrm{mm}}$ & $540103 \backslash \mathrm{mm} 3$ \\
\hline 9- 1137 wt $\mid w t+$ & $9.1310^{90 m e n s}$ & $15.48 \backslash d$ d & $43.4 \%$ & $7.910^{\text {rems }}$ & $52710^{\mathrm{nmm} 3}$ \\
\hline 10. J138 wt'wt+ & $10.2910^{\circ \mathrm{mmi}}$ & $17,3 \mathrm{~g} \backslash \mathrm{dl}$ & $50.0 \%$ & $11.310^{\mathrm{nmena}}$ & $52610^{1 / m m a}$ \\
\hline
\end{tabular}

Figura 4. Caracterização dos animais portadores da mutação Jak2V617F e controles. A. Esquema representativo do padrão de bandas em gel de agarose a 2\% para genotipagem dos animais Jak2 WT/WT e Jak2 WT/VF. B. Tamanho do baço dos animais Jak2 WT/WT (painel superior) e Jak2 WT/VF (painel inferior). C. Contagens diferenciais do hemograma de animais Jak2 WTWT e Jak2 WT/VF.

Wt: wild type; pb: pares de bases; MM: Marcador de peso molecular; GV: Glóbulos vermelhos; HGB: Hemoglobina; HCT: Hematócrito; GB: Glóbulos brancos e PLAQTs: Plaquetas. 


\subsection{Padronização do Isolamento das células mesenquimais}

\subsubsection{Avaliação da pureza de isolamento das células mesenquimais por meio de flushing de ossos longos}

Durante o cultivo das células isoladas dos ossos longos, observamos incialmente uma população celular heterogênea, caracterizada por diferenças morfológicas de tamanho e forma, sendo que algumas células apresentavam morfologia alongada e outras apresentam morfologia mais oval. Apesar da observação microscópica de que as células em cultura se tornavam mais homogêneas e fusiformes após a quinta passagem, além da marcação com CD135 por citometria de fluxo ter sido observada e demonstrar que havia células mesenquimais isoladas, obteve-se cultura com "contaminação" considerável por células hematopoéticas com este método de obtenção. A figura 4 ilustra, por meio de um experimento representativo de uma das tentativas de isolamento de células mesenquimais, a estratégia de análise da imunofenotipagem para identificação das células obtidas após a cultura de longa duração de material obtido por meio de flushing dos ossos longos de animais da colônia Jak2V617F. Foram utilizados marcadores de células hematopoéticas tais como CD45, F4-80 (monócitos/macrófagos), CD11b (granulócitos), CD34 (precursores hematopoéticos) e CD135 (células mesenquimais). 

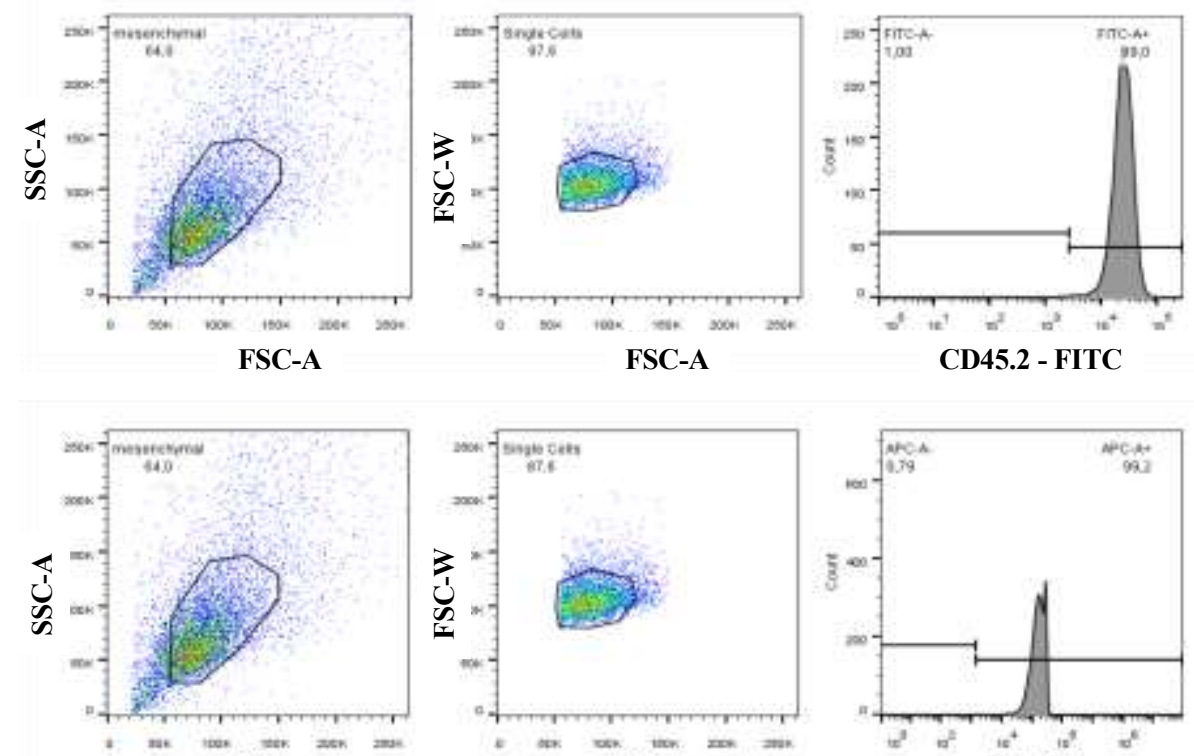

FSC-A
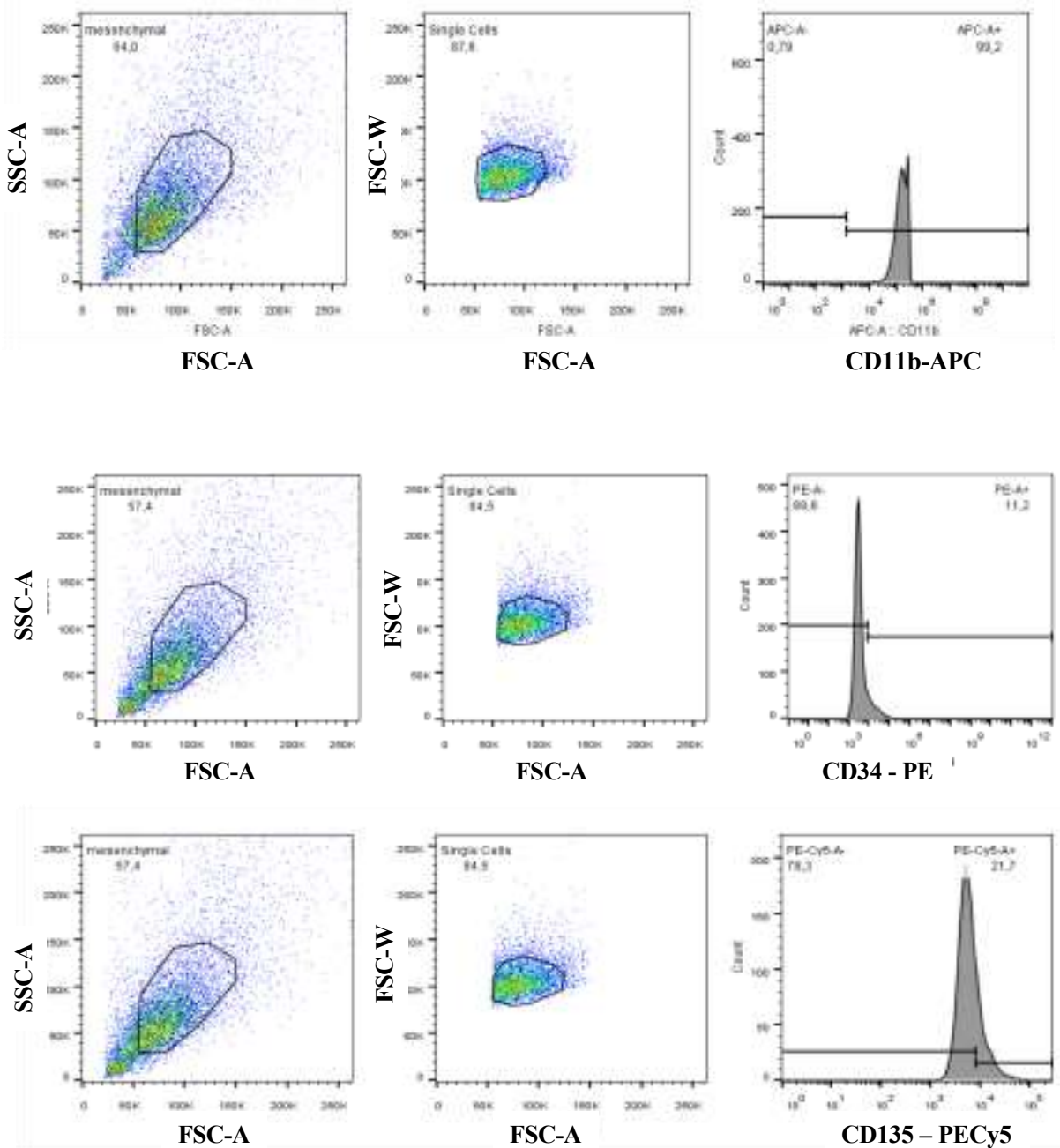

Figura 5. Estratégia de análise da imunofenotipagem por citometria de fluxo das células da medula óssea obtidas dos camundongos do modelo transgênico Jak2V617F para confirmação do isolamento de células mesenquimais por meio do método de flushing de ossos longos. Foram utilizados marcadores como CD45.2 para 
identificar células hematopoéticas em geral, $F 4 / 80$ e CD11b para identificação de macrófagos e células da linhagem mieloide, respectivamente, CD34 para identificar células progenitoras hematopoéticas e CD135 para células mesenquimais. Para análise da expressão de cada marcador, consideramos células não marcadas com os anticorpos do painel escolhido.

\subsubsection{Avaliação da pureza de isolamento das células mesenquimais por meio de digestão de ossos longos com colagenase I}

A confirmação da pureza das células mesenquimais isolada com processamento inicial por meio de digestão dos ossos longos com colagenase I foi realizada por meio da caracterização imunofenotípica, sendo estas definidas como células viáveis, negativas para CD45, CD31 e CD90, e positivas para os marcadores Sca-1 e CD51. Com essa estratégia, observamos uma pureza superior a $90 \%$ para as células mesenquimais obtidas de animais Jak2wt e Jak2VF (Figura 5B).

A)

\begin{tabular}{|c|c|c|}
\hline P1 & P2 & $P_{3}$ \\
\hline
\end{tabular}

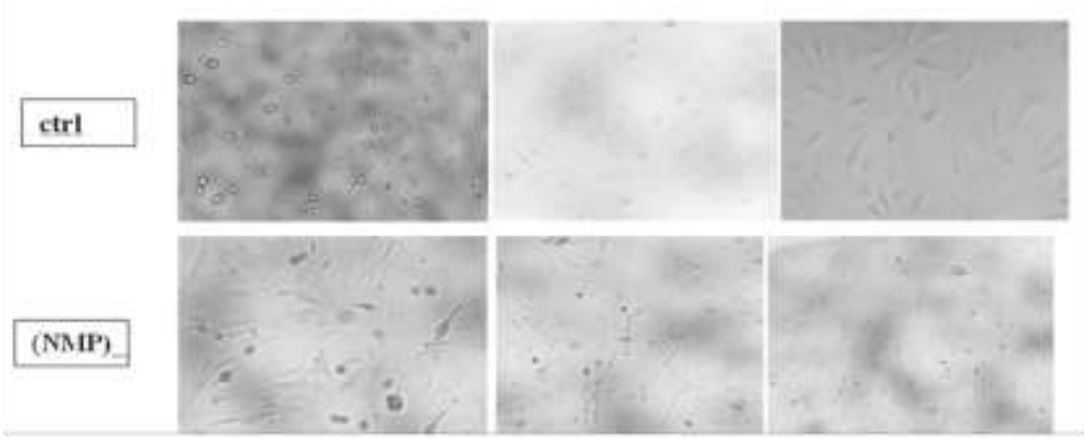

B)

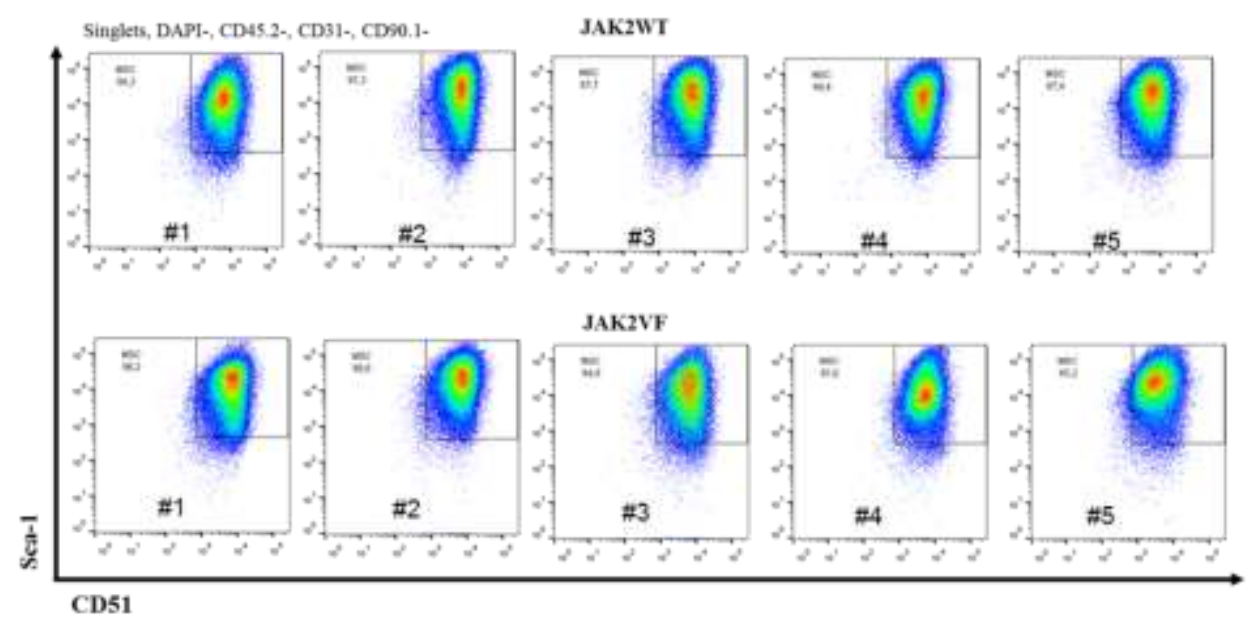


Figura 6. llustração da morfologia e imunofenotipagem de células mesenquimais isoladas por meio de digestão de ossos longos de animais do modelo transgênico Jak2V617F com colagenase I. A. Imagem representativa do isolamento das CMs por colagenase (passagens P11 a P3) de animais JAK2WT (controles) e JAK2VF (portadores da mutação V617F com neoplasia mieloproliferativa). B. Plots demonstrando a pureza das células mesenquimais após cultura de longa duração (5 passagens) por meio do fenótipo CD45-/CD31-/CD90-/CD51+/Sca-1+ de animais JAK2WT $(n=5)$ e JAK2VF $(n=5)$, analisados por citometria de fluxo.

\subsection{Avaliação da frequência dos componentes celulares do nicho endosteal em}

\section{animais Jak2VF em comparação aos controles Jak2wt}

Além do estabelecimento das metodologias para isolamento e cultura de longa duração de células mesenquimais estromais, realizamos experimentos de análise das populações de células do nicho endosteal imediatamente após o processamento da medula óssea dos animais pelo método de flushing e digestão com colagenase I. Esta análise consistiu em determinar a frequência relativa e números absolutos das células mesenquimais (CMs), osteoblastos (OBs) e células endoteliais (CEs) por análise de citometria de fluxo.

Para tanto, a população celular negativa para o CD45.2 e Ter-119 foi selecionada, foram utilizados os marcadores CD31 para identificação das CEs (CD31+/Sca-1-), CD51 para identificação dos OBs (CD51+/Sca-1-) e o Sca-1 para identificação das CMs (Sca-1+/CD51+).

Nossa análise das células obtidas após o flushing celular (consideradas como provenientes do nicho perivascular) demonstrou uma tendência à obtenção de um número inferior de células totais (Figura 7A) e OBs (Figura 7C) em animais Jak2VF quando comparados aos animais Jak2wt. Por outro lado, foi observada uma maior frequência de células endoteliais na medula óssea de animais Jak2VF em relação à medula óssea de animais Jak2wt ( $P=0.0079$, teste de Mann-Whitney, Figura 7D), embora isto não tenha sido confirmado pela contagem absoluta $(P=0.6900$, teste de 
Mann-Whitney). Por fim, não foram identificadas diferenças em frequência e/ou números absolutos das CMs do nicho obtidas por flushing (Figura 7B).

Diferentemente dos resultados observados quando as células da MO foram recuperadas por flushing, nenhuma tendência com relação ao número total de células recuperadas foi observada quando os fragmentos ósseos foram submetidos a digestão por colagenase (Figura 7E). Contudo, o número de $\mathrm{CMs}$, tanto em frequência $(P=0.0159$, teste de Mann-Whitney) quanto em valores absolutos $(P=$ 0.0079, teste de Mann-Whitney), foi significativamente menor nos animais Jak2VF quando comparados aos animais Jak2wt, após o tratamento com colagenase (Figura 7F). Com relação aos OBs, a redução absoluta em animais Jak2VF em comparação aos controles observada quando a amostra foi obtida por flushing foi confirmada quando a obtenção destas células foi realizada pela digestão com colagenase $(P=$ 0.0159, teste de Mann-Whitney, Figura 7G). De maneira semelhante aos resultados obtidos por flushing de ossos longos, a frequência relativa de células endoteliais esteve elevada na medula óssea dos animais Jak2VF $(P=0.0079$, teste de MannWhitney, Figura $7 \mathrm{H}$ ) comparada àquela de animais Jak2wt, embora não se tenha observado diferenças na quantificação absoluta.

É importante salientar que observamos um elevado desvio padrão nas amostras obtidas dos animais Jak2wt, o que pode ter comprometido algumas comparações entre os dois grupos.

Em resumo, demonstramos uma eficiente estratégia de isolamento e caracterização das células mesenquimais estromais do nicho da medula óssea por meio de digestão de fragmentos ósseos com colagenase I e cultura de longa duração para expansão destas células. Além disso, observamos menor frequência absoluta de CMs e OBs tanto no nicho perivascular como no nicho endosteal de 
camundongos transgênicos portadores de NMPS associada à mutação Jak2V617F em relação a animais controles (saudáveis e não portadores da mutação Jak2V617F).

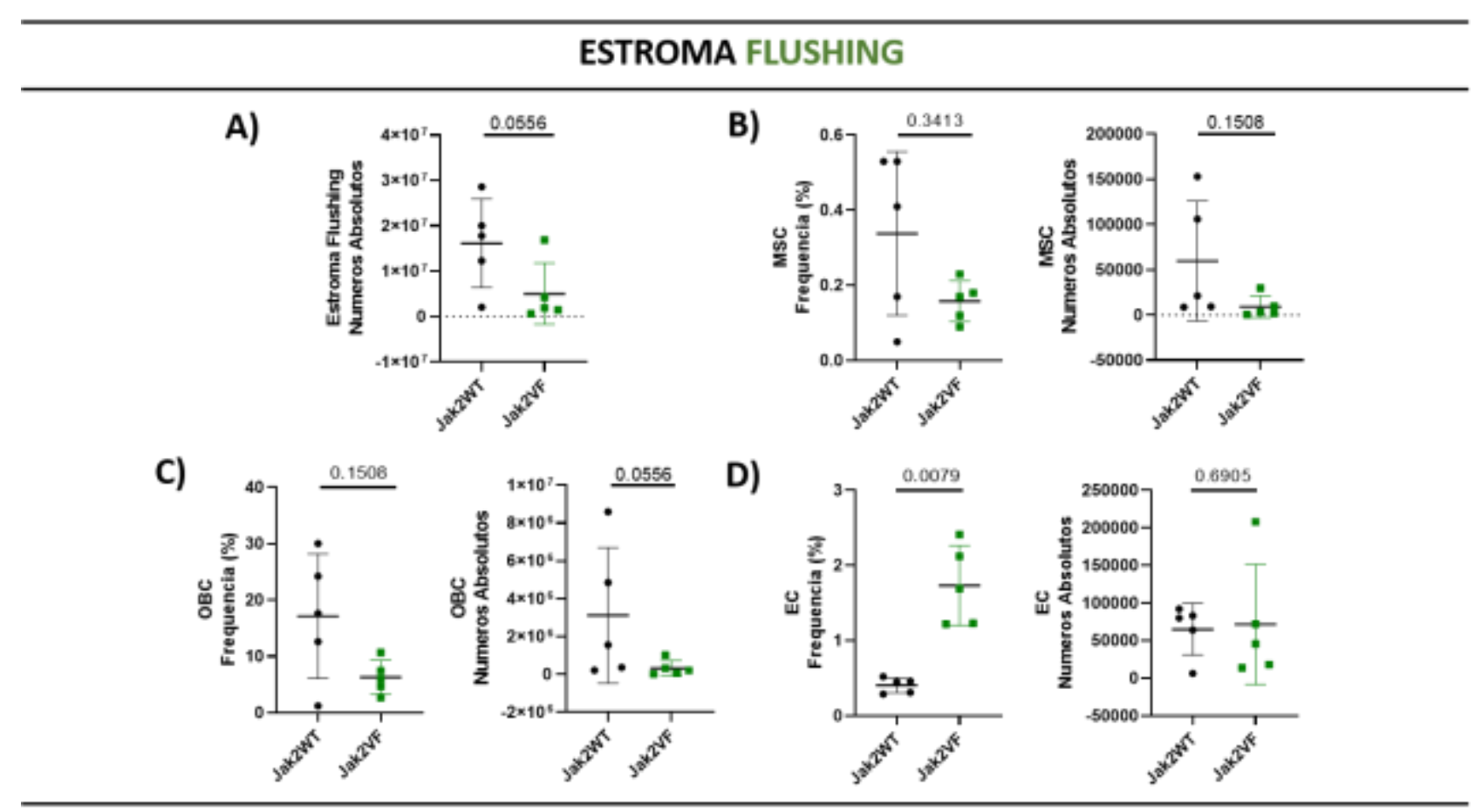

ESTROMA COLAGENASE

G)

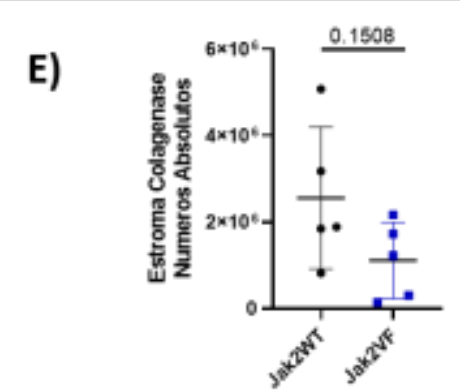

F)
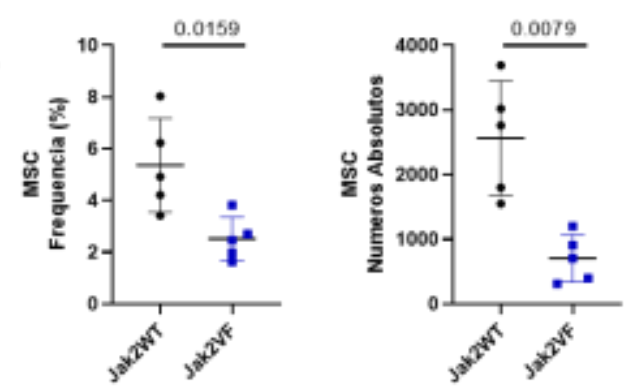

H)

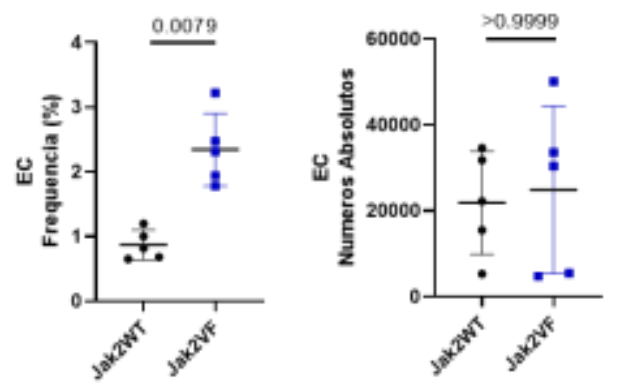

Figura 7. A neoplasia mieloproliferativa do modelo murino de expressão condicional da Jak2V617F se acompanha de menor frequência de células mesenquimais estromas, e osteoblastos. Frequência relativa e absoluta de células recuperadas da medula óssea de animais Jak2wt e Jak2VF por meio de flushing de ossos longos (A-D) ou digestão de fragmentos ósseos com colagenase I (E-H). (A e E) células totais, (B e F) CMs 
(C e G) OBs (D e H) ECs. CMs: células mesenquimais; OBs: osteoblastos; ECs: células endoteliais. Comparações estatísticas realizadas por meio de teste: Mann Whitney, sendo valores de $\mathrm{P}$ demonstrados e significância atribuída quando valores de $\mathrm{P} \leq 0.05$. 


\section{DISCUSSÃO}

A fisiopatologia das neoplasias mieloproliferativas (NMPS) crônicas é principalmente explicada pela presença de mutações somáticas que afetam as células-tronco hematopoéticas (CTHs), tais como JAK2V617F, CALR e MPL, que estimulam a proliferação mieloide desenfreada por meio de ativação da via JAK/STAT, e estão alternadamente presentes em mais de $90 \%$ dos pacientes com policitemia vera, trombocitemia essencial e mielofibrose primária (NANGALIA; GREEN, 2014). Além da desregulação intrínseca das CTHs das NMPs, sinais externos produzidos por outras células da medula óssea, como as células do nicho, podem contribuir para a propagação das células neoplásicas e, consequentemente, para a expansão dos progenitores mieloides, favorecendo as manifestações clínicas da doença. Apesar de todo este conhecimento acerca do mecanismo molecular dirigido pela mutação JAK2 nestas neoplasias, escasso é o conhecimento sobre a interação das CTHs carregando a mutação JAK2 com o microambiente medular. Estudos recentes apontam que a interação entre a CTH maligna e as células estromais é um importante fator no desenvolvimento e curso da doença (ARRANZ et al., 2014a; SCHEPERS et al., 2013c).

Para o melhor entendimento das alterações funcionais no microambiente das NMPs, utilizamos o modelo murino transgênico Jak2V617F para caracterização das células estromais da medula óssea (MO), comparando os animais Jak2VF com a contraparte saudável Jak2wt. Para isto, comparamos dois métodos de isolamento das células estromais da MO: o flushing celular e a digestão por colagenase, em relação a quantificação da composição dos nichos perivascular e endosteal, compostos basicamente por células tronco mesenquimais (CMs), osteoblastos (OBs) e células endoteliais (CEs). 
Neste contexto, o trabalho de Arranz e colaboradores (ARRANZ et al., 2014a) demonstrou uma significante redução das células mesenquimais nestin+, localizadas nos nervos simpáticos de pacientes com NMPs bem como no modelo murino contendo a mutação JAK2. Este estudo corrobora nossos resultados que também demonstraram uma significante redução no número de CMs (em frequência e número absoluto), quando os ossos longos de animais Jak2VF foram submetidos à digestão com colagenase para o isolamento das células endosteais. Em contrapartida, não observamos significância na redução de CMs quando apenas o flushing de células da medula óssea foi utilizado no isolamento, o que seria um efeito esperado visto que as células mesenquimais nestin+ fazem parte da região perivascular da MO (MÉNDEZ-FERRER et al., 2010b). Acreditamos que um dos fatores limitantes que poderiam explicar estes resultados contraditórios seria o fato da metodologia de flushing não ser tão eficiente em isolar as células do nicho sem contaminação por células hematopoéticas.

Ademais, o trabalho de Arranz e colaboradores (ARRANZ et al., 2014b) descreve que a redução do número de células mesenquimais nestin+ é causado pelo aumento da secreção de IL-1 $\beta$ pelas CTHs. Deste modo, seria interessante investigar se este mecanismo se dá apenas pela secreção elevada de IL-1 $\beta$ pelas CTHs ou se, em paralelo, ocorre a síntese da molécula anti-inflamatória antagonista da IL1, a IL-1RA pelas CMs que encontram-se alteradas no contexto da mutação JAK2 (ORTIZ et al., 2007).

Pouco se sabe sobre a função dos OBs nas NMPs. Apesar de grande número de CTHs serem encontradas em proximidade às células endoteliais, no chamado nicho perivascular, sabe-se que há uma população de reserva de CTHs quiescentes e com elevado potencial de autorrenovação a longo prazo no chamado endósteo, 
próximo à região trabecular, onde se encontram os osteoblastos. Dessa forma, é possível que haja regulação entre osteoblastos e CTHs no contexto fisiológico bem como no desenvolvimento de neoplasias mieloides.

Nossos resultados indicam uma tendência a um número reduzido de OBs nas regiões ósseas perivascular e endosteal. Em contraste com os nossos resultados, o trabalho de Schepers e colaboradores (SCHEPERS et al., 2013c), descreveu um aumento na proliferação dos OBs dirigida pela trombopoetina e CCL3, utilizando um modelo murino transgênico de leucemia mieloide crônica (LMC), associada à $\mathrm{t}(9 ; 22 / B C R-A B L 1)$. Embora estes resultados não estejam de acordo com os nossos, é importante salientar que os autores utilizaram outro modelo de NMPs cuja fisiopatologia está ligada à proliferação celular dirigida pela ativação constitutiva da proteína $A B L 1$, diferente do que ocorre na transformação das células-tronco leucêmicas por mutações que ativam a via JAK/STAT. Considerando esta diferença molecular e celular entre os dois modelos de NMPs, a extrapolação de resultados obtidos a partir de modelos de LMC para o entendimento da fisiopatologia das NMPs BCR-ABL1-negativas não nos parece a melhor estratégia para o entendimento do microambiente medular. Essa comparação também nos permite supor que entidades moleculares distintas (como por exemplo as NMPs dirigidas por mutações nos genes JAK2, MPL e/ou CALR) possam levar a diferentes mecanismos de interação entre as CTHs mutadas e as células do microambiente da $\mathrm{MO}$, contribuindo para a heterogeneidade fenotípica que é observada no contexto clínico das NMPs.

Em concordância com os nossos dados, um estudo publicado em 2016 por Oikonomidou e colaboradores, descreveu reduzida atividade dos osteoblastos bem como da massa óssea em animais Jak2V617F knockin, embora os mecanismos celulares envolvidos neste processo não tenham sido esclarecidos (OIKONOMIDOU 
et al., 2016). Adicionalmente, Bowers e colaboradores demonstraram que a ablação de osteoblastos resultou em perda de quiescência, enxertia e capacidade de autorrenovação de CTHs normais, promovendo um microambiente propício à proliferação celular. Em um modelo murino de NMPS BCR-ABL1+, observaram progressão mais rápida da leucemia e menor sobrevida dos animais (\{Citation\}). Assim, estudos futuros para determinar o papel funcional dos osteoblastos nas NMPs ainda são necessários e de interesse para a comunidade médica e científica.

Em conjunto, nossos dados sugerem que a supressão dos componentes do nicho endosteal (células mesenquimais e osteoblastos) favoreça a expansão das células-tronco leucêmicas no modelo de NMPS associada à mutação Jak2V617F. Uma maneira de melhor elucidar esse mecanismo seria investigar os efeitos de osteoblastos do microambiente anormal de NMPS sobre a frequência, proliferação e potencial de autorrenovação de CTHs normais.

Ao analisarmos a frequência e número absoluto das CEs nos animais Jak2wt e Jak2VF, observamos frequência significativamente maior nos animais Jak2mutados em comparação aos animais controles, independente da metodologia de isolamento aplicada (flushing ou colagenase). Curiosamente, estudos recentes reportaram a presença da mutação Jak2V617F em células endoteliais de pacientes com NMPs, sendo a presença da mutação associada com o desenvolvimento de trombose (ROSTI et al., 2013; SOZER et al., 2009; TEOFILI et al., 2011).

Zhan e colaboradores mostraram que camundongos transgênicos no qual o nicho vascular continha CEs Jak2V617F mutadas apresentavam vantagem de expansão de CTHs Jak2-mutadas e ao desenvolvimento de proliferação mieloide em relação a CTHs controles quando submetidos a transplante de medula óssea competitivo (). Em nosso modelo murino transgênico, condicional e dependente do 
promotor vavCre, a mutação Jak2V617F encontra-se presente em todas as células hematopoéticas bem como nas células endoteliais, recapitulando o que já foi descrito para pacientes com NMPS. Assim, a expressão da Jak2V617F nas CEs pode explicar o seu aumento de frequência relativa e contribuir para a ocorrência de trombose nos animais, que tem sobrevida média de 120-150 dias, sendo a principal causa de morte já relatada a ocorrência de trombose intra-abdominal.

Pode-se ressaltar ainda que a padronização do isolamento e expansão de células do estroma da medula óssea dos animais Jak2V617F foi realizada pela primeira vez no laboratório onde esta pesquisa foi desenvolvida e contribuiu para este trabalho bem como para o desenvolvimento de outros projetos envolvendo o nicho hematopoético. Células armazenadas em várias passagens bem como RNA e sobrenadante das células mesenquimais para análise de citocinas foram obtidos e servirão para a continuação da investigação de regulação anômala entre nicho e células-tronco leucêmicas neste modelo de neoplasia mieloide.

Por fim, consideramos que o desequilíbrio entre componentes do nicho endosteal e vascular, exemplificado pela demonstração de redução da frequência de CMs e OBs e predominância de CEs Jak2-mutadas em relação aos controles, pode contribuir para a proliferação mieloide descontrolada característica das NMPs. Estudos funcionais são necessários para fortalecer tal hipótese, mas podemos dizer que o trabalho contribuiu para o conhecimento sobre o papel da regulação extrínseca das células-tronco leucêmicas por um nicho anormal, e que pode ser alvo terapêutico adicional à inibição da sinalização JAK/STAT. 


\section{CONCLUSÕES}

Concluímos que os resultados iniciais da cultura de células da medula óssea do modelo murino de NMPs Jak2V617F pelo método de flushing não foram satisfatórios para isolamento de uma população pura de células do nicho endosteal devido à contaminação com células hematopoéticas.

Obtivemos maior pureza (98\%) de isolamento de células mesenquimais estromais com a adoção da digestão com colagenase $\mathrm{I}$, o que possibilitou armazenamento de células, RNA e sobrenadante de cultura para estudos futuros.

No nicho perivascular, observamos uma tendência à redução no número de células totais em animais portadores da mutação Jak2 em relação aos controles. Em concordância, células mesenquimais e osteoblastos se mostraram reduzidos nos animais portadores de NMPs.

No nicho endosteal, embora a quantificação total de células não tenha sido diferente entre animais controles e Jak2VF, observamos menor frequência de células mesenquimais e osteoblastos nos animais Jak2VF em relação aos controles Jak2wt. 


\section{REFERÊNCIAS}

ARAI, F. et al. Tie2/Angiopoietin-1 Signaling Regulates Hematopoietic Stem Cell Quiescence in the Bone Marrow Niche. Cell, v. 118, n. 2, p. 149-161, jul. 2004a.

ARAI, F. et al. Tie2/Angiopoietin-1 Signaling Regulates Hematopoietic Stem Cell Quiescence in the Bone Marrow Niche. Cell, v. 118, n. 2, p. 149-161, jul. 2004b.

ARBER, D. A. et al. The 2016 revision to the World Health Organization classification of myeloid neoplasms and acute leukemia. Blood, v. 127, n. 20, p. 2391-2405, 19 maio 2016.

ARRANZ, L. et al. Neuropathy of haematopoietic stem cell niche is essential for myeloproliferative neoplasms. Nature, v. 512, n. 7512, p. 78-81, ago. 2014a.

ARRANZ, L. et al. Neuropathy of haematopoietic stem cell niche is essential for myeloproliferative neoplasms. Nature, v. 512, n. 7512, p. 78-81, ago. 2014b.

BAXTER, E. J. et al. Acquired mutation of the tyrosine kinase JAK2 in human myeloproliferative disorders. The Lancet, v. 365, n. 9464, p. 1054-1061, mar. 2005.

BUTLER, J. M. et al. Endothelial Cells Are Essential for the Self-Renewal and Repopulation of Notch-Dependent Hematopoietic Stem Cells. Cell Stem Cell, v. 6, n. 3, p. 251-264, mar. 2010.

CALVI, L. M. et al. Osteoblastic cells regulate the haematopoietic stem cell niche. Nature, v. 425, n. 6960, p. 841-846, out. 2003.

FUCHS, E.; TUMBAR, T.; GUASCH, G. Socializing with the neighbors: stem cells and their niche. Cell, v. 116, n. 6, p. 769-778, 19 mar. 2004.

GRIESINGER, F. et al. ABCR-JAK2 fusion gene as the result of a $t(9 ; 22)(p 24 ; q 11.2)$ translocation in a patient with a clinically typical chronic myeloid leukemia. Genes, Chromosomes and Cancer, v. 44, n. 3, p. 329-333, nov. 2005.

KASTRINAKI, M.-C. et al. Mesenchymal Stem Cells in Immune-Mediated Bone Marrow Failure Syndromes. Clinical and Developmental Immunology, v. 2013, p. 1-10, 2013.

KIEL, M. J. et al. SLAM Family Receptors Distinguish Hematopoietic Stem and Progenitor Cells and Reveal Endothelial Niches for Stem Cells. Cell, v. 121, n. 7, p. 1109-1121, jul. 2005.

KOBAYASHI, $\mathrm{H}$. et al. Angiocrine factors from Akt-activated endothelial cells balance self-renewal and differentiation of haematopoietic stem cells. Nature Cell Biology, v. 12, n. 11, p. 1046-1056, nov. 2010.

KONOPLEVA, M. Y.; JORDAN, C. T. Leukemia Stem Cells and Microenvironment: Biology and Therapeutic Targeting. Journal of Clinical Oncology, v. 29, n. 5, p. 591-599, 10 fev. 2011.

KRALOVICS, R. et al. A Gain-of-Function Mutation of JAK2 in Myeloproliferative Disorders. New England Journal of Medicine, v. 352, n. 17, p. 1779-1790, 28 abr. 2005.

KRAUSE, D. S.; SCADDEN, D. T.; PREFFER, F. I. The hematopoietic stem cell niche-home for friend and foe? Cytometry Part B: Clinical Cytometry, v. 84B, n. 1, p. 7-20, jan. 2013a.

KRAUSE, D. S.; SCADDEN, D. T.; PREFFER, F. I. The hematopoietic stem cell niche--home for friend and foe? Cytometry. Part B, Clinical Cytometry, v. 84, n. 1, p. 7-20, fev. 2013b.

MAJUMDAR, M. K. et al. Human Marrow-Derived Mesenchymal Stem Cells (MSCs) Express Hematopoietic Cytokines and Support Long-Term Hematopoiesis When 
Differentiated Toward Stromal and Osteogenic Lineages. Journal of Hematotherapy \& Stem Cell Research, v. 9, n. 6, p. 841-848, dez. 2000.

MAURO, M.; O'DWYER, M.; DRUKER, B. STI571, a tyrosine kinase inhibitor for the treatment of chronic myelogenous leukemia: validating the promise of molecularly targeted therapy. Cancer Chemotherapy and Pharmacology, v. 48, n. 0, p. S77S78, 1 jul. 2001a.

MAURO, M.; O'DWYER, M.; DRUKER, B. STI571, a tyrosine kinase inhibitor for the treatment of chronic myelogenous leukemia: validating the promise of molecularly targeted therapy. Cancer Chemotherapy and Pharmacology, v. 48, n. 0, p. S77S78, 1 jul. 2001b.

MÉNDEZ-FERRER, S. et al. Mesenchymal and haematopoietic stem cells form a unique bone marrow niche. Nature, v. 466, n. 7308, p. 829-834, ago. 2010a.

MÉNDEZ-FERRER, S. et al. Mesenchymal and haematopoietic stem cells form a unique bone marrow niche. Nature, v. 466, n. 7308, p. 829-834, ago. 2010b.

MORRISON, S. J.; SCADDEN, D. T. The bone marrow niche for haematopoietic stem cells. Nature, v. 505, n. 7483, p. 327-334, jan. 2014.

MÜLLER-SIEBURG, C. E. et al. Deterministic regulation of hematopoietic stem cell self-renewal and differentiation. Blood, v. 100, n. 4, p. 1302-1309, 15 ago. 2002.

NANGALIA, J.; GREEN, T. R. The evolving genomic landscape of myeloproliferative neoplasms. Hematology. American Society of Hematology. Education Program, v. 2014, n. 1, p. 287-296, 5 dez. 2014.

OIKONOMIDOU, P. R. et al. Polycythemia is associated with bone loss and reduced osteoblast activity in mice. Osteoporosis International, v. 27, n. 4, p. 1559-1568, abr. 2016.

OMATSU, Y. et al. The Essential Functions of Adipo-osteogenic Progenitors as the Hematopoietic Stem and Progenitor Cell Niche. Immunity, v. 33, n. 3, p. 387-399, set. 2010.

ORTIZ, L. A. et al. Interleukin 1 receptor antagonist mediates the antiinflammatory and antifibrotic effect of mesenchymal stem cells during lung injury. Proceedings of the National Academy of Sciences, v. 104, n. 26, p. 11002-11007, 26 jun. 2007.

PARK, D. The hematopoietic stem cell niche. Frontiers in Bioscience, v. 17, n. 1, p. 30, 2012.

PELED, A. Dependence of Human Stem Cell Engraftment and Repopulation of NOD/SCID Mice on CXCR4. Science, v. 283, n. 5403, p. 845-848, 5 fev. 1999.

PERRY, J. M.; LI, L. Disrupting the Stem Cell Niche: Good Seeds in Bad Soil. Cell, v. 129 , n. 6, p. 1045-1047, jun. 2007.

PETIT, I. et al. G-CSF induces stem cell mobilization by decreasing bone marrow SDF-1 and up-regulating CXCR4. Nature Immunology, v. 3, n. 7, p. 687-694, jul. 2002.

PRASANNA, S. J. et al. Pro-Inflammatory Cytokines, IFNy and TNFa, Influence Immune Properties of Human Bone Marrow and Wharton Jelly Mesenchymal Stem Cells Differentially. PLoS ONE, v. 5, n. 2, p. e9016, 2 fev. 2010.

REYA, T. et al. Stem cells, cancer, and cancer stem cells. Nature, v. 414, n. 6859, p. 105-111, nov. 2001.

ROSTI, V. et al. Spleen endothelial cells from patients with myelofibrosis harbor the JAK2V617F mutation. Blood, v. 121, n. 2, p. 360-368, 10 jan. 2013.

SCADDEN, D. T. The stem cell niche in health and leukemic disease. Best Practice \& Research Clinical Haematology, v. 20, n. 1, p. 19-27, mar. 2007. 
SCHEPERS, K. et al. Myeloproliferative Neoplasia Remodels the Endosteal Bone Marrow Niche into a Self-Reinforcing Leukemic Niche. Cell Stem Cell, v. 13, n. 3, p. 285-299, set. 2013a.

SCHEPERS, K. et al. Myeloproliferative Neoplasia Remodels the Endosteal Bone Marrow Niche into a Self-Reinforcing Leukemic Niche. Cell Stem Cell, v. 13, n. 3, p. 285-299, set. 2013b.

SCHEPERS, K. et al. Myeloproliferative Neoplasia Remodels the Endosteal Bone Marrow Niche into a Self-Reinforcing Leukemic Niche. Cell Stem Cell, v. 13, n. 3, p. 285-299, set. 2013c.

SCHMITT-GRAEFF, A. H.; NITSCHKE, R.; ZEISER, R. The Hematopoietic Niche in Myeloproliferative Neoplasms. Mediators of Inflammation, v. 2015, p. 1-11, 2015.

SCHOFIELD, R. The relationship between the spleen colony-forming cell and the haemopoietic stem cell. Blood Cells, v. 4, n. 1-2, p. 7-25, 1978.

SOTIROPOULOU, P. A.; PAPAMICHAIL, M. Immune Properties of Mesenchymal Stem Cells. In: VEMURI, M. C. (Ed.). . Stem Cell Assays. Methods in Molecular Biology. Totowa, NJ: Humana Press, 2007. v. 407p. 225-243.

SOZER, S. et al. The presence of JAK2V617F mutation in the liver endothelial cells of patients with Budd-Chiari syndrome. Blood, v. 113, n. 21, p. 5246-5249, 21 maio 2009.

TEOFILI, L. et al. Endothelial progenitor cells are clonal and exhibit the JAK2V617F mutation in a subset of thrombotic patients with Ph-negative myeloproliferative neoplasms. Blood, v. 117, n. 9, p. 2700-2707, 3 mar. 2011.

VAINCHENKER, W.; KRALOVICS, R. Genetic basis and molecular pathophysiology of classical myeloproliferative neoplasms. Blood, v. 129, n. 6, p. 667-679, 9 fev. 2017.

VALTIERI, M.; SORRENTINO, A. The mesenchymal stromal cell contribution to homeostasis. Journal of Cellular Physiology, v. 217, n. 2, p. 296-300, nov. 2008.

WALKLEY, C. R. et al. A Microenvironment-Induced Myeloproliferative Syndrome Caused by Retinoic Acid Receptor y Deficiency. Cell, v. 129, n. 6, p. 1097-1110, jun. 2007.

WANG, $\mathrm{H}$. et al. Hierarchical organization and regulation of the hematopoietic stem cell osteoblastic niche. Critical Reviews in Oncology/Hematology, v. 85, n. 1, p. 18, jan. 2013.

WATT, F. M. Out of Eden: Stem Cells and Their Niches. Science, v. 287, n. 5457, p. 1427-1430, 25 fev. 2000.

YODER, M. C. et al. Redefining endothelial progenitor cells via clonal analysis and hematopoietic stem/progenitor cell principals. Blood, v. 109, n. 5, p. 1801-1809, 1 mar. 2007.

YOSHIHARA, $\mathrm{H}$. et al. Thrombopoietin/MPL Signaling Regulates Hematopoietic Stem Cell Quiescence and Interaction with the Osteoblastic Niche. Cell Stem Cell, v. 1, n. 6, p. 685-697, dez. 2007.

ZHANG, J. et al. Identification of the haematopoietic stem cell niche and control of the niche size. Nature, v. 425, n. 6960, p. 836-841, 23 out. 2003.

$\mathrm{ZHU}, \mathrm{H}$. et al. A protocol for isolation and culture of mesenchymal stem cells from mouse compact bone. Nature Protocols, v. 5, n. 3, p. 550-560, mar. 2010. 


\section{ANEXO}

\section{Parecer do Comitê de Ética em Animais}

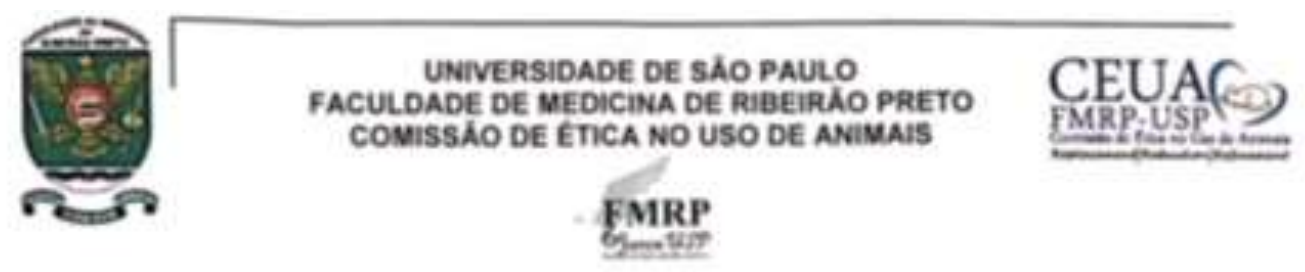

\section{CERTIFICADO}

Centificamos que o Protocolo intitulado "Caracterisaplo do nicho endostral do mudula distea nas neoplasias mielopreliferativas associadas d mutaplo da LAK2", registrado com o nimeto 172/2017, sob a responsabilidale do Prof. Dr. Eduardo Magalthies Rega, envolvendo a produclo, manutenglo ou utiliracso de animais penencentes ao filo Chordata, subfilo Vertelvata (exceto humanos) para fins de pespuisa cientifica, encottra-se de acordo com es preceitos da Lei $n^{*} 11.794$ de 8 de cutubro de 2008, do Decreto $n^{*} 6.899$ de 15 de julho de 2009 e com as normas editadas pelo Conselho Nacional de Controle de Experimentaclo Animal (CONCEA) e foi AProvaDo pela Comisulo de Etica no Uso de Animais da Faculdade de Medicina de Ribeirlo Preto da Universidade de SSo Paulo ens reunilo de 30 de outubro de 2017.

Este Protocolo peve a wailiraclo de 40 carnandongos WT machos pesando 228 e 40 camundongos KO JAK2 machos pesando $24 \mathrm{~g}$. eriundos do Laboratório de Estados Experimentais em Animais do Hemocentro da Faculdade de Medicina de Ribeirlo Preto da Universidade de Sto Paula. Vigtncia da matorizaclo: 3010/2017 a 22/11/2022.

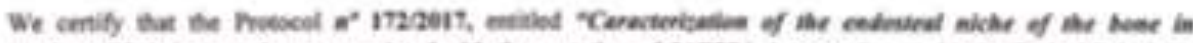

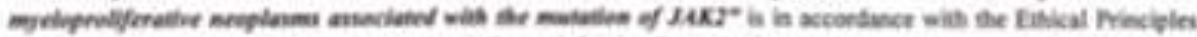

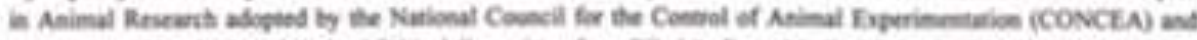

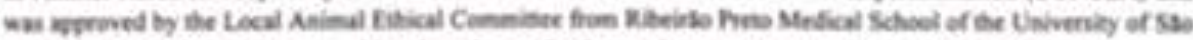

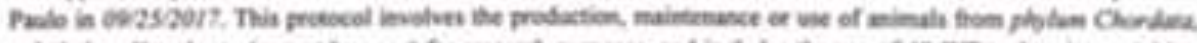

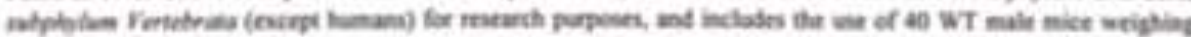

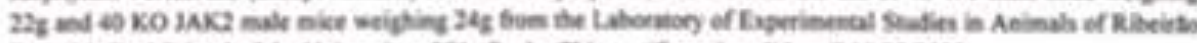

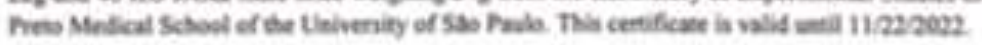

Ribeirlo Preta, 30 de outubro de 2017

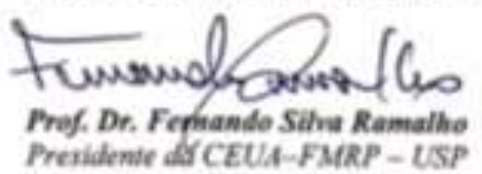

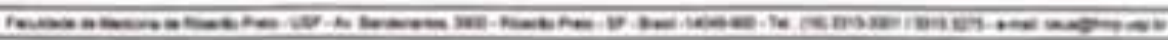

